\title{
Characterizing the Local and Intense Water Cycle during a Cold Air Outbreak in the Nordic Seas ${ }^{\mathfrak{O}}$
}

\author{
LUKAS PAPRITZ ${ }^{\mathrm{a}}$ AND HARALD SODEMANN \\ Geophysical Institute, University of Bergen, and Bjerknes Centre of Climate Research, Bergen, Norway
}

(Manuscript received 14 May 2018, in final form 22 August 2018)

\begin{abstract}
Air masses in marine cold air outbreaks (CAOs) at high latitudes undergo a remarkable diabatic transformation because of the uptake of heat and moisture from the ocean surface, and the formation of precipitation. In this study, the fundamental characteristics of the water cycle during an intense and persistent, yet archetypal basinwide CAO from Fram Strait into the Nordic seas are analyzed with the aid of the tracerenabled mesoscale limited-area numerical weather prediction model COSMO. A water budget of the CAO water cycle is performed based on tagged water tracers that follow moisture picked up by the CAO at various stages of its evolution. The atmospheric dynamical factors and boundary conditions that shape this budget are thereby analyzed. The water tracer analysis reveals a highly local water cycle associated with the CAO. Rapid turnover of water vapor results in an average residence time of precipitating waters of about one day. Approximately one-third of the total moisture taken up by the CAO falls as precipitation by convective overturning in the marine CAO boundary layer. Furthermore, precipitation efficiency increases as the CAO air mass matures and is exposed to warmer waters in the Norwegian Sea. These properties of the $\mathrm{CAO}$ water cycle are in strong contrast to situations dominated by long-range moisture transport that occur in the dynamically active regions of extratropical cyclones. It is proposed that CAOs in the confined Nordic seas provide a natural laboratory for studying local characteristics of the water cycle and evaluating its representation in models.
\end{abstract}

\section{Introduction}

Located at the end of the North Atlantic storm track, the Nordic seas frequently experience configurations of the large-scale flow that are dominated by mature and deep cyclones (Wernli and Schwierz 2006; Dacre and Gray 2009; Jahnke-Bornemann and Brümmer 2008). These cyclones bring about strongly contrasting atmospheric conditions, varying rapidly on a time scale of hours to days. Incursions of warm and moist air masses from southerly latitudes in the cyclone's warm sector are accompanied by intense precipitation as the air masses ascend in the so-called warm conveyor belt

Supplemental information related to this paper is available at the Journals Online website: https://doi.org/10.1175/MWR-D-180172.s1.

\footnotetext{
${ }^{a}$ Current affiliation: Institute for Atmospheric and Climate Science, ETH Zürich, Zürich, Switzerland.
}

Corresponding author: Lukas Papritz, lukas.papritz@env.ethz.ch (e.g., Browning 1990; Madonna et al. 2014) or are steered toward the steep orographic rise along the western Norwegian coast (Stohl et al. 2008; Azad and Sorteberg 2017). These warm conditions are subsequently followed by the advection of cold and dry Arctic air masses behind the cyclone's cold front. The Arctic air masses are typically colder than the underlying sea surface, and are therefore favorable for inducing so-called marine cold air outbreaks (CAOs; Wacker et al. 2005; Brümmer et al. 2005; Papritz and Grams 2018).

CAOs are associated with a remarkably intense thermodynamic transformation of a dry and cold, stably stratified Arctic air mass into a much warmer and relatively humid, convectively unstable air mass that can bring precipitation downstream (e.g., Papritz and Spengler 2017). Because of the strong air-sea temperature contrast, CAOs give rise to intense fluxes of heat and moisture from the ocean into the atmosphere (Shapiro et al. 1987; Grossman and Betts 1990; Brümmer 1996, 1997; Wacker et al. 2005) and vigorous convective mixing (Hartmann et al. 1997; Brümmer 1999; Renfrew and Moore 1999). 
Furthermore, the high baroclinicity at the CAO's edge and the low vertical stability provide an environment favorable for the formation of mesoscale cyclones and polar lows (Businger and Reed 1989; Rasmussen and Turner 2003; Kolstad 2011). The strong uptake of moisture by the CAO air mass together with intense convective motions often results in heavy snowfall (e.g., Shapiro et al. 1987; Kristovich et al. 2000; Wang et al. 2016), and it provides latent energy for the intensification of mesocyclones (Rasmussen and Turner 2003; Terpstra et al. 2015), which in turn strongly amplify the decay of the CAO (Papritz and Pfahl 2016). In consequence, diabatic processes play a dominant role in the evolution of CAOs. Their simulation with numerical models, as well as of the related weather phenomena, relies strongly on parameterized, subgrid-scale processesmore so than the simulation of other, less diabatic flows. Consequently, CAOs provide a natural environment for evaluating parameterized, subgrid-scale processes. A detailed understanding of the mechanisms driving the thermodynamic transformation of such CAO air masses including their associated water cycle is, therefore, beneficial for evaluating and improving the representation of CAOs in models as much as for our fundamental understanding of the role of CAOs in the climate system.

From a climatological perspective, CAOs are the major drivers of heat and moisture fluxes from the ocean into the atmosphere over most of the Nordic seas (Harden et al. 2015; Papritz and Spengler 2017). Compensating a substantial fraction of the freshwater input into the ocean by precipitation, CAOs are, furthermore, an important cause of the relatively small magnitude of the winter mean net atmospheric freshwater flux into the Nordic seas-especially in the Greenland and Iceland Seas (Segtnan et al. 2011). As CAOs are highly episodic events (e.g., Kolstad 2017), small variations in their frequency of occurrence during one winter season could impose substantial anomalies on the winter mean atmosphere-ocean buoyancy flux. This can have important implications for deep convection in the ocean that contributes dense water to the lower limb of the Atlantic meridional overturning circulation (e.g., Marshall and Schott 1999). Consequently, our aims in this study are to quantify the net footprint of the CAO water cycle in freshwater fluxes (i.e., evaporation minus precipitation) and to study the dynamical factors and boundary conditions that govern its spatial variations.

The evolution of the boundary layer structure of CAOs has been investigated extensively based on observations at high latitudes (e.g., Brümmer 1996, 1997; Hartmann et al. 1997; Renfrew and Moore 1999; Vihma and Brümmer 2002;
Wang et al. 2016). While most of these studies did not specifically focus on the water cycle, Brümmer (1997) compiled boundary layer budgets of moisture as a function of distance from the sea ice edge for 11 CAOs from Fram Strait into the Greenland and Norwegian Seas based on aircraft measurements. Complementary to such observational studies, modeling studies of CAOs have been conducted on a wide range of spatial scales. They include two-dimensional models to simulate the downstream evolution of the turbulent boundary layer along sections extending several hundred kilometers away from the sea ice edge (e.g., Lüpkes and Schlünzen 1996; Vihma and Brümmer 2002; Chechin et al. 2013), large-eddy simulations to investigate the convective organization and vertical transfer of heat and moisture in a subregion of the CAO (e.g., Skyllingstad and Edson 2009; Gryschka et al. 2014; Tomassini et al. 2017), and mesoscale models to study the dynamical evolution and erosion of CAO air masses (Pagowski and Moore 2001; Wacker et al. 2005; Papritz and Pfahl 2016). However, no systematic study has so far been conducted on the fundamental characteristics of the basin-scale water cycle during CAOs, and it is the major goal of this study to close this gap.

An especially fruitful method to diagnose the characteristics of the water cycle using numerical models is by means of water vapor tracers (e.g., Bosilovich and Schubert 2002). These tracers are released by evaporation from specified source regions or by transport of water vapor across a certain box or surface, such as, for example, the lateral boundaries of a limited-area model. Previously, this water vapor tagging approach has been employed for investigating water vapor isotopes (Joussaume et al. 1984; Pfahl et al. 2012), sources and recycling of precipitating waters from a climatological perspective (Koster et al. 1986; Numaguti 1999; Bosilovich and Schubert 2002), and case studies of moisture uptake and transport contributing to heavy precipitation events (Sodemann et al. 2009; Winschall et al. 2012, 2014) as well as of water vapor transport associated with atmospheric rivers along the North Atlantic storm track (Sodemann and Stohl 2013).

In this study, we employ a limited-area numerical weather prediction model with a water vapor tagging implementation to simulate the hydrological cycle associated with a major CAO that occurred in the Nordic seas between 24 and 27 December 2015. This event was one of the most intense and long-lived CAOs in recent decades, while being fairly typical in terms of formation mechanisms and airmass pathways. We consider the moisture budget of this CAO using tagged water tracers to follow moisture that evaporated within the $\mathrm{CAO}$ and during different 
(a)

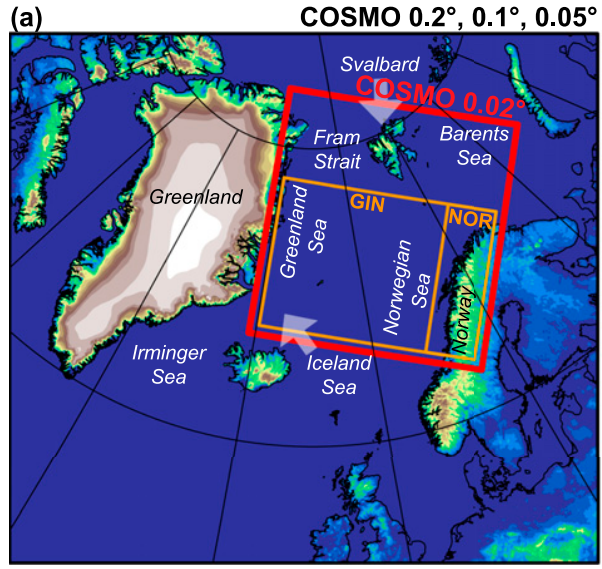

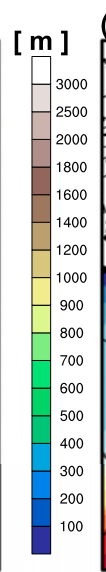

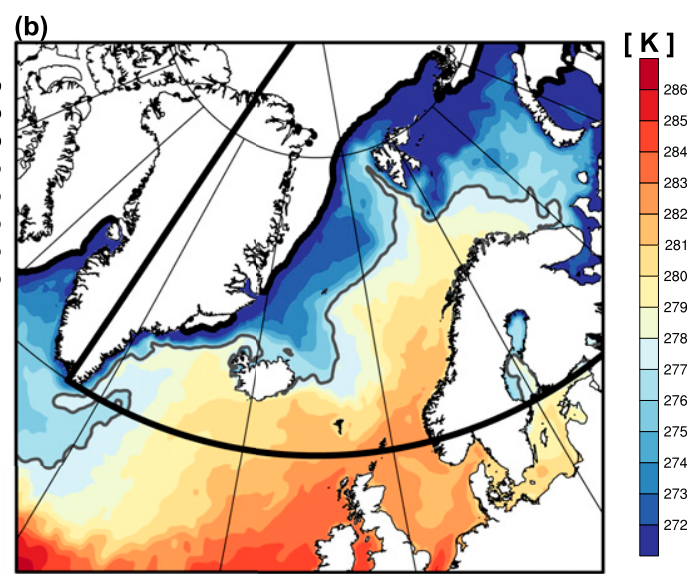

FIG. 1. (a) Domain of the COSMO $0.2^{\circ}, 0.1^{\circ}$, and $0.05^{\circ}$ simulations and the nested domain of the COSMO $0.02^{\circ}$ simulations (red frame). The shading indicates model topography in the COSMO $0.05^{\circ}$ simulation. Furthermore, the regions over which precipitation is integrated are indicated by the orange boxes (GIN and NOR boxes) and key locations are marked. (b) Sea surface temperature (shading) with the location of the Arctic front highlighted by the 277-K isotherm (gray line) and the sea ice edge (thick black). The black box outlines the region in which evaporation into the CAO air mass is tagged.

phases of its development to address the following questions:

- How much water is extracted from the ocean surface during the CAO?

- How much is precipitated within the CAO area?

- How much is deposited at the surrounding topography as the CAO air masses impinge on the topographic barriers?

- How much leaves the region of the CAO, impacting the budget elsewhere?

These aspects of the CAO's water budget are related to the turnover rate and lifetime of water vapor evaporating during this event. Furthermore, we will show that they are closely related to the dynamic and thermodynamic boundary conditions, including the sea surface temperature (SST) and location of the Arctic front (the sharp SST gradient separating the cold waters in the Greenland and Iceland Seas from the warm waters in the Norwegian Sea; cf. Fig. 1b), as well as the sea ice edge and the large-scale atmospheric flow. A set of model simulations provides insight into the sensitivity of the results with respect to model resolution and parameterized convection.

The methodology is introduced in the subsequent section, followed by an overview of the synoptic evolution of the CAO and its linkage to low- and upper-tropospheric large-scale flow features, as well as the uptake, transport, and sink of vapor associated with the CAO in section 3 . In section 4 the principal characteristics of the CAO water cycle are identified and their robustness with respect to model resolution is assessed in section 5, followed by conclusions in section 6 .

\section{Methods}

\section{a. The COSMO model}

Simulations are performed with the mesoscale numerical weather prediction model of the Consortium for Small-Scale Modeling (COSMO; Steppeler et al. 2003; Baldauf et al. 2011), version 4.18. This model is in operational use at various weather services, for example, the German and the Swiss national weather services, and it has previously been employed for process studies of CAOs and in the marginal ice zone (Wacker et al. 2005; Schröder et al. 2011; Papritz and Pfahl 2016), as well as for studying the water cycle (Winschall et al. 2014).

The COSMO model solves the thermodynamichydrodynamic equations on a rotated latitude-longitude grid with height-based terrain following a vertical coordinate. It comprises a set of state-of-the-art physical parameterizations (cf. Doms et al. 2011). This includes schemes for representing subgrid-scale turbulence using a level-2.5-closure based on turbulent kinetic energy, moist convection based on the mass-flux scheme by Tiedtke (1989), as well as microphysics using a onemoment two-category ice scheme with prognostic variables for water vapor, cloud water, cloud ice, rain, and snow. The representation of microphysics in the convection parameterization is a simplified version of the large-scale microphysics. For simulations at partly convection-resolving resolution, the model offers a nonprecipitating shallow convection scheme following Tiedtke (1989) that parameterizes the nonresolved portions of shallow convective mixing of heat and moisture. Furthermore, a thermodynamic sea ice model with 
prognostic sea ice thickness and surface temperature is used (Schröder et al. 2011).

For the purpose of studies of air-sea interaction processes in CAOs, the Coupled Ocean-Atmosphere Response Experiment (COARE) bulk air-sea heat and momentum flux parameterization (Fairall et al. 1996, 2003) has been added to the COSMO model (cf. Papritz and Pfahl 2016). The transfer of heat and momentum parameterized with this scheme has been validated against and compares particularly well with in situ observations at high wind speeds of up to $20 \mathrm{~m} \mathrm{~s}^{-1}$ (Fairall et al. 2003; Cook and Renfrew 2015). In this study we use the COARE parameterization over open ocean grid cells, while over land and sea ice the parameterization by Louis (1979) is employed.

\section{b. Water vapor tagging}

The idea of water vapor tagging is to extend the model by a secondary water cycle using tracers that represent water from specified sources without affecting the primary prognostic fields in the model. Here, we use the tagging implementation for the COSMO model of Winschall et al. (2014), building on previous work by Sodemann et al. (2009). The secondary water cycle comprises a complete set of prognostic tracer variables for the five water species represented in the model (i.e., water vapor, cloud water, cloud ice, rainwater, and snow). The tracers are released via the advection across the lateral boundaries into the model domain and the evaporation from the surface in specifically defined regions. Likewise, sinks of the tracers are the advection out of the model domain and precipitation within the domain. The prognostic tracer fields undergo the same resolved and subgrid-scale processes as the prognostic fields from the primary water cycle, but they do not affect the simulated meteorology. The transfer rates required for phase changes between tracer species are taken as proportional to the fraction of tagged water represented by the tracer times the total transfer rate obtained from the primary water cycle (Sodemann et al. 2009).

In this study seven distinct tracers are introduced to investigate the CAO water cycle. These CAO tracers represent water entering the domain via evaporation from the ocean surface into the originally essentially dry CAO air mass. To identify the CAO air mass, we use the air-sea potential temperature difference $\theta_{\mathrm{SST}}-\theta_{900}$, with $\theta_{\text {SST }}$ and $\theta_{900}$ denoting potential SST and potential temperature at $900 \mathrm{hPa}$, respectively. This follows previous studies that employed variants of $\theta_{\mathrm{SST}}-\theta_{900}$ for the identification of marine CAOs (e.g., Bracegirdle and Gray 2008; Kolstad 2011; Fletcher et al. 2016; Papritz and Spengler 2017). Positive values of this CAO index indicate an air mass that is colder than the underlying sea surface. Here, we define the evaporation region of the CAO tracers as the area where $\theta_{\mathrm{SST}}-\theta_{900}$ exceeds $4 \mathrm{~K}$. This selects moderate to very strong CAO air masses, while neglecting regions where the air-sea temperature contrast is only weakly positive, with correspondingly weak upward surface heat fluxes (cf. Papritz and Spengler 2017). The evaporation region is updated with each model time step and therefore follows the evolution of the CAO. To make sure that only evaporation into the main $\mathrm{CAO}$ air mass originating from Fram Strait is considered, the evaporation region of the CAO tracers is limited to the area poleward of $60^{\circ} \mathrm{N}$ and eastward of $45^{\circ} \mathrm{W}$ (cf. black frame in Fig. 1b).

An overview of the time windows during which the CAO tracers are released via evaporation from the ocean surface is given in Fig. 2. After their respective release windows all tracers are carried through the entire remaining model integration. A new CAO tracer is initialized every $12 \mathrm{~h}$ until 1200 UTC 26 December $(+72 \mathrm{~h})$, thus yielding six CAO tracers that are released in 12-hourly intervals. An additional seventh CAO tracer is defined for the time after 1200 UTC 26 December $(+72 \mathrm{~h}$; blue and green bars, Fig. 2). Finally, two more tracers are introduced to (i) represent water that is initially present in the model domain (gray bar, Fig. 2) and (ii) water newly entering the domain during the simulation via advection across the lateral boundaries and via evaporation from land, sea ice, and ocean outside of the CAO evaporation region (red bar, Fig. 2).

This setup should in principle allow us to represent all water within the primary water cycle by the tracers. Because of numerical inconsistencies, however, minor differences between tagged and total water can occur (Sodemann et al. 2009; Sodemann and Stohl 2013). Throughout all simulations, these differences are always less than $1 \%$ of the total vapor and precipitation, respectively.

To obtain an estimate of the atmospheric residence time (i.e., the atmospheric age of precipitating waters) tagged precipitation is assigned to 12 -hourly bins according to the maximum time that could have occurred since evaporation given the 12-hourly release intervals of the tracers. For example, precipitation at $t=18 \mathrm{~h}$ that evaporated from the ocean surface between 0 and $12 \mathrm{~h}$ could have evaporated $6-18 \mathrm{~h}$ ago and is therefore assigned to the second bin (evaporation less than $24 \mathrm{~h}$ ago), whereas precipitation that evaporated between 12 and $18 \mathrm{~h}$ is assigned to the first bin (evaporation less than $12 \mathrm{~h}$ ago). Accordingly, these estimates represent upper limits for the residence time and the actual values may be lower.

\section{c. Model configuration}

Numerical models in general have difficulties adequately simulating the convective and turbulent motions 


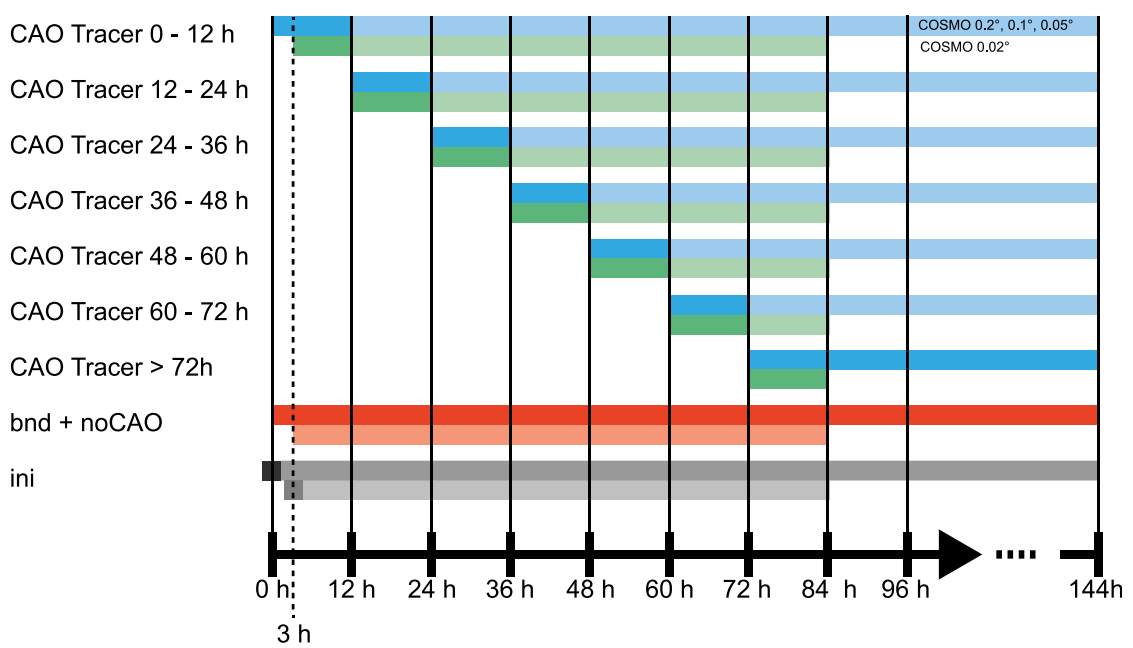

FIG. 2. Temporal definition of the tracers. Blue and green stand for CAO tracers where strong (weak) colors indicate the time window during which the tracer is released (carried through the model integration but no longer released), red is for the tracer representing water entering the domain by advection across the domain boundaries and by evaporation into non$\mathrm{CAO}$ air masses, and gray is for the tracer representing water initially present in the domain. The dashed vertical line indicates the initialization time of the $0.02^{\circ} \times 0.02^{\circ}$ simulations. The upper and lower horizontal bars refer to the definition of the tracers in the COSMO $0.2^{\circ}, 0.1^{\circ}$, $0.05^{\circ}$ and COSMO $0.02^{\circ}$ simulations, respectively, which have different initialization and forecast lead times (cf. Table 1).

in CAOs at grid spacings of several kilometers (i.e., in the so-called convective gray zone) (Field et al. 2017; Tomassini et al. 2017). Consequently, a set of simulations at four different grid spacings ranging from $0.2^{\circ} \times$ $0.2^{\circ}$ to $0.02^{\circ} \times 0.02^{\circ}$ is performed to assess the robustness of the identified characteristics of the CAO water cycle in terms of grid spacing. Table 1 gives an overview of the simulations and corresponding model configurations. While for the COSMO $0.2^{\circ}$ to COSMO $0.05^{\circ}$ simulations the full Tiedtke (1989) convection scheme is used, two simulations at a grid spacing of $0.02^{\circ} \times 0.02^{\circ}$ are performed: one with explicit convection only (COSMO $0.02^{\circ} \mathrm{nc}$ ) and one with the shallow convection scheme active (COSMO $\left.0.02^{\circ} \mathrm{sc}\right)$. Operational analyses from the European Centre for Medium-Range Weather Forecasts (ECMWF) at a 6-hourly interval serve as initial and boundary conditions for the COSMO $0.2^{\circ}$, COSMO $0.1^{\circ}$, and $\operatorname{COSMO} 0.05^{\circ}$ simulations. The analyses are interpolated onto the rotated model grid with the North Pole chosen such that the equator runs across the model domain [i.e., the pole is located at $16^{\circ} \mathrm{N}$, $170^{\circ} \mathrm{E}$ in geographical coordinates (cf. Fig. 1a for domain)]. The simulations are initialized at 1200 UTC 23 December about $12 \mathrm{~h}$ before the CAO air mass is advected over open ocean (see section 3 ) and the model is subsequently integrated for $144 \mathrm{~h}$.

For computational reasons the COSMO $0.02^{\circ}$ simulations are run on a smaller domain that is nested into the COSMO $0.05^{\circ}$ domain (red box Fig. 1a). The initial and boundary conditions for these simulations are taken from the hourly output of the COSMO $0.05^{\circ}$ simulation and interpolated onto the nested grid with its North Pole at $20^{\circ} \mathrm{N}, 160^{\circ} \mathrm{E}$ in geographical coordinates. For simplicity, tracers from the water vapor tagging are not

TABLE 1. Model configurations for the five simulations. The COSMO $0.02^{\circ}$ simulations are run in the nested domain, while the other simulations are run on the full domain (cf. Fig. 1a). The grid size denotes the dimensions of the grid in the zonal, meridional, and vertical direction, respectively.

\begin{tabular}{|c|c|c|c|c|c|}
\hline Name & Horizontal grid spacing & Grid size & Initialization time & Duration & Convection scheme \\
\hline $\operatorname{COSMO} 0.2^{\circ}$ & $0.2^{\circ} \times 0.2^{\circ}$ & $200 \times 180 \times 40$ & 1200 UTC 23 Dec & $144 \mathrm{~h}$ & Tiedtke (1989) \\
\hline $\operatorname{COSMO} 0.1^{\circ}$ & $0.1^{\circ} \times 0.1^{\circ}$ & $400 \times 360 \times 60$ & 1200 UTC 23 Dec & $144 \mathrm{~h}$ & Tiedtke (1989) \\
\hline COSMO $0.05^{\circ}$ & $0.05^{\circ} \times 0.05^{\circ}$ & $800 \times 720 \times 60$ & 1200 UTC 23 Dec & $144 \mathrm{~h}$ & Tiedtke (1989) \\
\hline COSMO $0.02^{\circ} \mathrm{nc}$ & $0.02^{\circ} \times 0.02^{\circ}$ & $800 \times 840 \times 60$ & 1500 UTC 23 Dec & $81 \mathrm{~h}$ & None \\
\hline COSMO $0.02^{\circ} \mathrm{sc}$ & $0.02^{\circ} \times 0.02^{\circ}$ & $800 \times 840 \times 60$ & 1500 UTC 23 Dec & $81 \mathrm{~h}$ & reduced Tiedtke (1989) (shallow) \\
\hline
\end{tabular}


(a) 201512240000 UTC

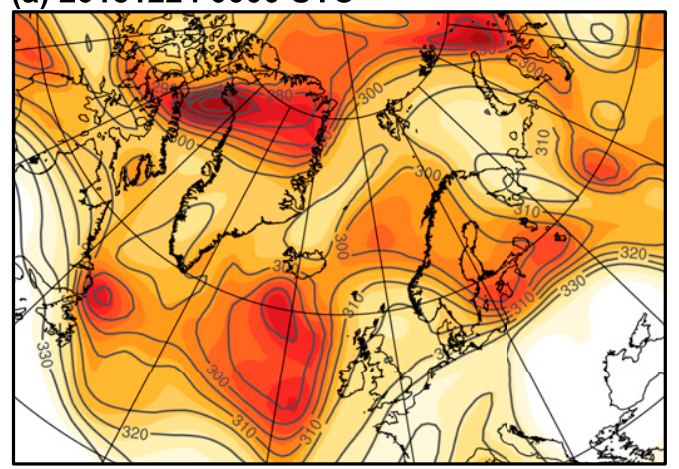

(c) 201512260000 UTC

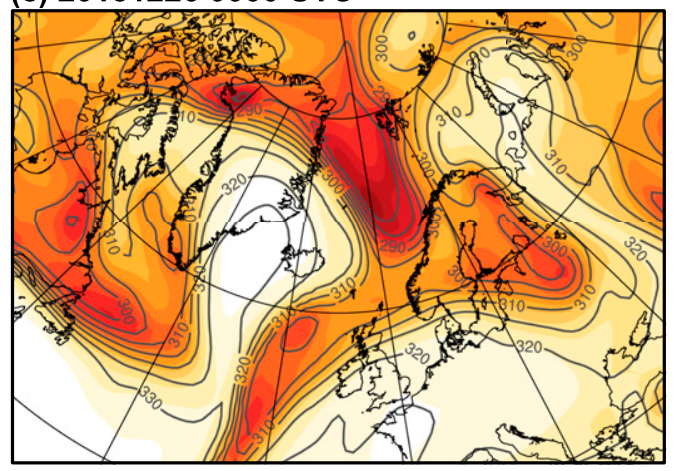

(b) 201512250000 UTC

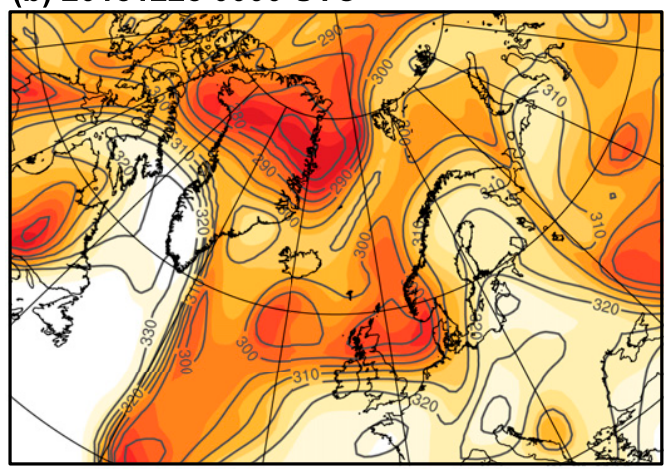

(d) 201512270000 UTC

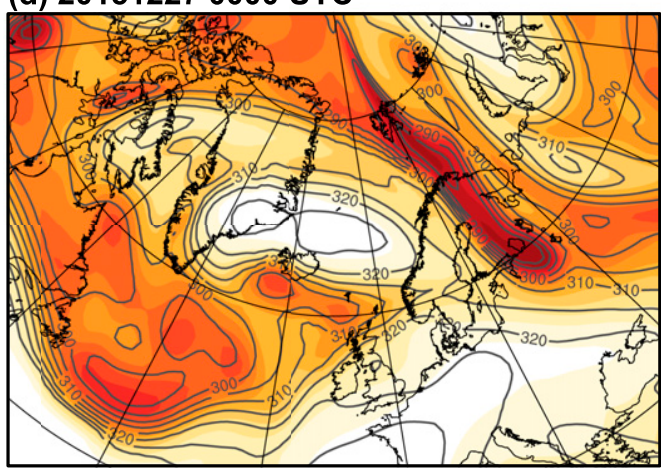

[hPa]

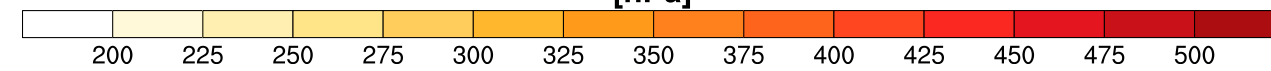

FIG. 3. Temporal evolution of pressure (shading) and potential temperature (gray, contour interval $5 \mathrm{~K}$ ) at the dynamical tropopause from (a) 0000 UTC 24 Dec to (d) 0000 UTC 27 Dec in daily intervals. Data are from the ERA-Interim reanalysis (Dee et al. 2011). The dynamical tropopause is defined as the 2-PVU potential vorticity isosurface (1 PVU $=10^{-6} \mathrm{~K} \mathrm{~kg}^{-1} \mathrm{~m}^{2} \mathrm{~s}^{-1}$; cf. Hoskins et al. 1985; Škerlak et al. 2015).

prescribed from the COSMO $0.05^{\circ}$ simulation at the domain boundaries. Instead, moisture advected into the nested domain is considered as not originating from the CAO. Since the domain covers most of the region along the sea ice edge where CAO air masses are advected over open ocean and there is only weak recirculation of CAO air masses out and subsequently again into the domain (cf. section 3), only a negligible amount of CAO moisture is erroneously considered as non-CAO moisture because of this simplification. The COSMO $0.02^{\circ}$ simulations are initialized at 1500 UTC 23 December and integrated for $81 \mathrm{~h}$ until 0000 UTC 27 December. Consequently, the release window of the first CAO tracer is only $9 \mathrm{~h}$ such that the CAO tracers remain synchronized in all simulations (lower bars Fig. 2).

In all simulations, the evolution of the large-scale horizontal structure of the CAO is in close agreement with operational analyses from the ECMWF (see Fig. S1 in the online supplemental material) and the thermodynamic profiles compare favorably with radiosonde observations (e.g., Fig. S2 in the supplemental material). Throughout this study, the COSMO $0.05^{\circ}$ simulation will serve as the reference simulation. It will also be used to discuss the evolution of the CAO and establish the principal characteristics of the CAO water cycle in sections 3 and 4 . Based on the additional simulations, the robustness of these characteristics will be assessed in section 5 .

\section{Evolution of the CAO event}

\section{a. Synoptic overview}

In this section, we will give an overview of the synoptic evolution of the CAO based on ERA-Interim reanalysis data (Fig. 3) and the COSMO $0.05^{\circ}$ simulation (Fig. 4). To that end, we will visualize the pool of cold air in the interior Arctic and the export of the CAO air mass into the Nordic seas in a quasi-Lagrangian manner by depicting the evolution of the mass located below a specific isentropic surface $\theta_{T}$ and the ground, the so-called cold 
(a) 201512240000 UTC

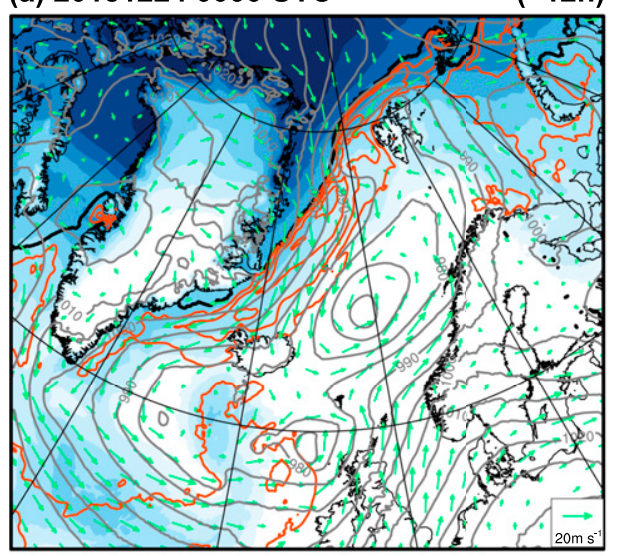

(c) 201512260000 UTC

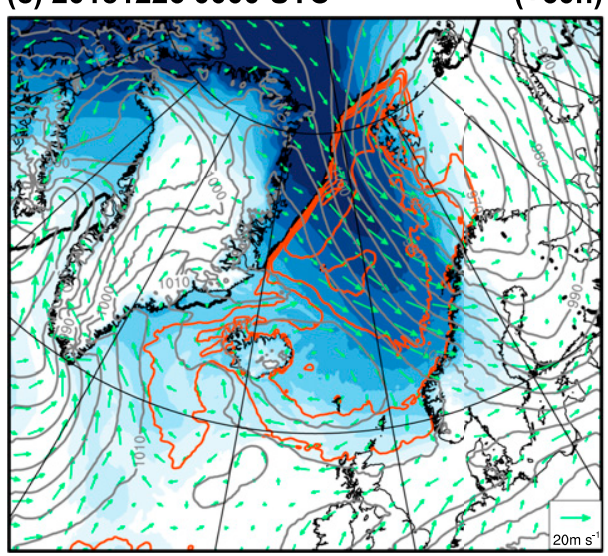

(b) 201512250000 UTC

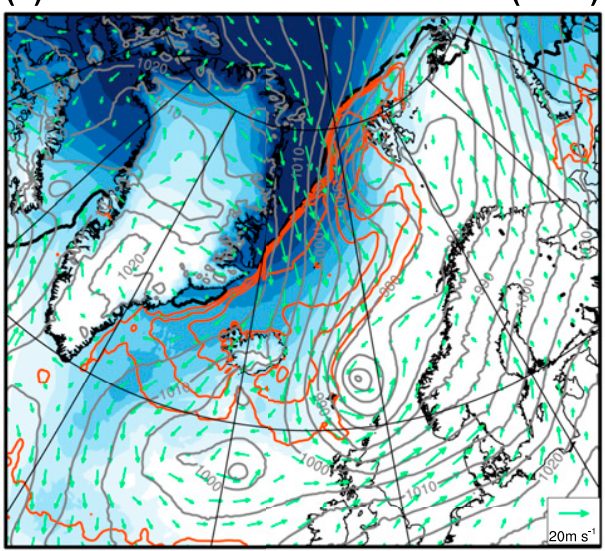

(+36h)

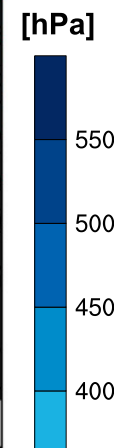

(d) 201512270000 UTC

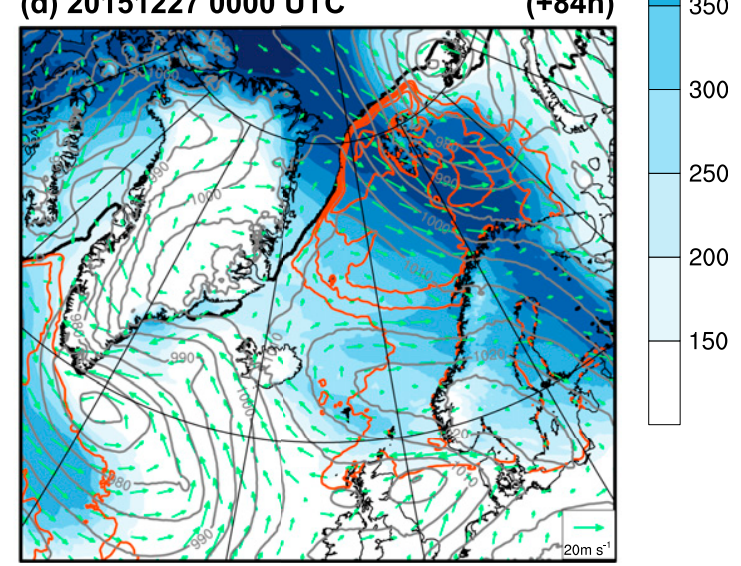

FIG. 4. Synoptic evolution of the cold air outbreak from (a) 0000 UTC 24 Dec to (d) 0000 UTC 27 Dec in daily intervals. Shown are cold air mass (mass below $280-\mathrm{K}$ isentropic surface in hPa; shading), CAO index $\left(\theta_{\mathrm{SST}}-\theta_{900}\right.$; red, contours from $4 \mathrm{~K}$ in intervals of $4 \mathrm{~K}$ ), sea level pressure (gray, contours in intervals of $5 \mathrm{hPa}$ ), winds on lowest model level ( $\sim 10 \mathrm{~m}$ above ground, green arrows), and the sea ice edge (thick black). Data are from the COSMO $0.05^{\circ}$ simulation.

air mass (Iwasaki et al. 2014; Papritz and Pfahl 2016). The choice of $\theta_{T}$ is informed by the maximum SST to which the CAO air mass is exposed while in the Norwegian Sea, which amounts to slightly more than $280 \mathrm{~K}$ (cf. Fig. 1b). All air leaving the interior Arctic with a potential temperature below $280 \mathrm{~K}$ has the possibility to contribute to the CAO. We thus use a threshold of $\theta_{T}=280 \mathrm{~K}$.

The formation of the CAO and its evolution are closely linked to a positive potential vorticity anomaly in the lower stratosphere, which is characterized by a low-lying and cold tropopause (Fig. 3a) and an upward doming of isentropic surfaces below [i.e., anomalously cold air; cf. Hoskins et al. (1985)]. This feature has its origin over northwestern Greenland (Fig. 3a), which is a region favorable for the genesis of such lowerstratospheric positive potential vorticity anomalies (Kew et al. 2010). It subsequently translates toward Fram Strait and into the Greenland Sea (Fig. 3b), accompanied by the advection of particularly cold air across the sea ice edge into the Nordic seas underneath. The latter is evident from the thick tongue of cold air that forms in the Nordic seas (red; Figs. 4a-c), as well as an increasing air-sea potential temperature contrast (red contours). A persistent and intense lower-tropospheric transport of cold air is established by the strengthening of the pressure gradient on the rearward side of an extensive surface trough in the Norwegian Sea (gray contours and green arrows; Fig. 4b). Furthermore, a mesoscale cyclone west of the Svalbard archipelago episodically enhances the transport of cold air over Fram Strait during the initial stage of the CAO.

As evident from the lowering of the tropopause to nearly $500 \mathrm{hPa}$, the further evolution of the CAO is steered by the filamentation and strengthening of the upper-level feature, and the formation of an elongated dome of cold air mass underneath that stretches from the sea ice edge across the Nordic seas all the way 
(a) AVHRR

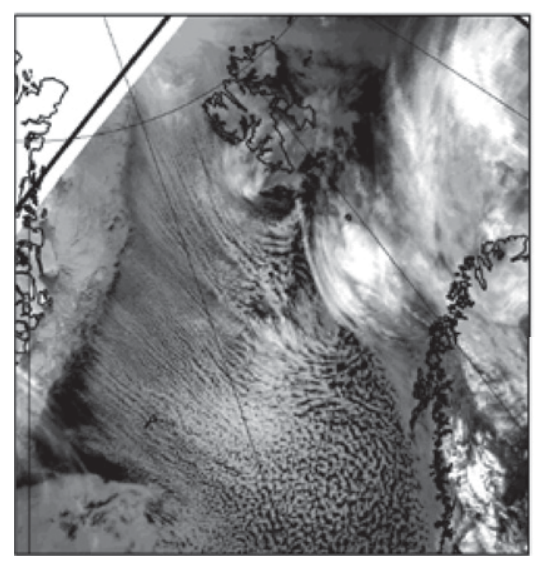

(b) $\operatorname{cosMO} 0.02^{\circ} \mathrm{nc}$

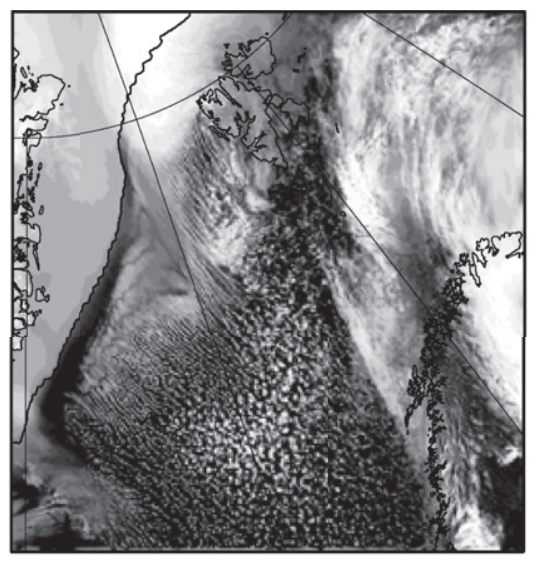

(c) $\operatorname{cosmo~} 0.02^{\circ} \mathrm{sc}$

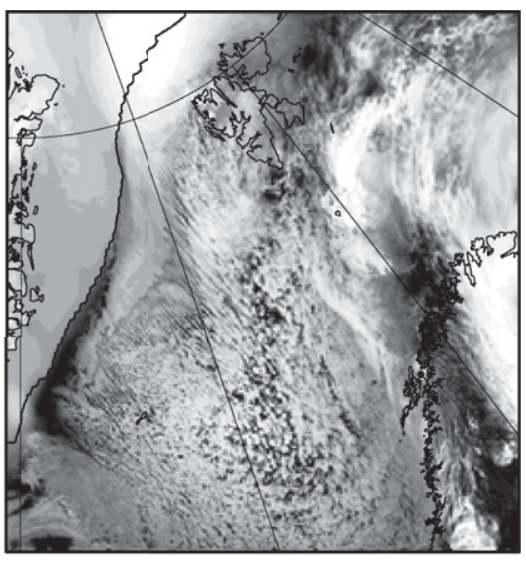

FIG. 5. (a) Infrared (channel 4) satellite image from the NOAA-17 AVHRR instrument valid at 1935 UTC 25 Dec 2015. (b),(c) Top of the atmosphere outgoing longwave radiation in the COSMO $0.02^{\circ} \times 0.02^{\circ}$ simulation (b) without (nc) and (c) with (sc) shallow convection parameterization at 1900 UTC 25 Dec 2015.

toward Norway (Figs. 3c and 4c). Consequently, the airsea potential temperature difference attains values well above $12 \mathrm{~K}$ over large portions of the Nordic seasindicative of a very intense $\mathrm{CAO}$ accompanied by surface turbulent heat fluxes well in excess of $600 \mathrm{~W} \mathrm{~m}^{-2}$ (not shown). The cold front that marks the edge of the $\mathrm{CAO}$ and extends throughout the entire troposphere makes landfall in Norway on early 26 December (Fig. 4c). While the upper-level feature and the cold airmass tongue subsequently extend farther across Scandinavia and translate northeastward (Figs. $4 \mathrm{~d}$ and $3 \mathrm{~d}$ ), the strong lower-tropospheric pressure gradient across the Nordic seas and the associated rapid export of cold air from the interior Arctic via Fram Strait are sustained until 27 December (Fig. 4d).

The coevolution of the upper-level feature and the CAO suggests a dynamical coupling of the upper-level flow and the formation of the CAO. In particular, the eastward propagation of the upper-level front that is associated with the lowering of the tropopause induces lifting and consequently reinforces the surface trough in the Norwegian Sea and the development of the mesocyclone west of Svalbard, thus enhancing the pressure gradient that steers the export of the cold air from the interior Arctic. A similar coupling of upper- and lowlevel flow during CAO formation has previously been noted in a case study of a CAO in the South Pacific (Papritz and Pfahl 2016). In climatological terms, the formation of the CAO on the rearward side of a surface trough with its center in the Norwegian and Barents Seas corresponds to one of the archetypal synoptic configurations leading to CAOs that extend across the entire basin of the Nordic seas (cf. Kolstad et al. 2009; Papritz and Grams 2018). Furthermore, the export of cold air from the interior Arctic via Fram Strait and the subsequent flow across the Arctic front toward the Norwegian coast, is one of the principal pathways taken by air masses that contribute to CAOs in the Nordic seas (Papritz and Spengler 2017). From this climatological perspective, this CAO is a typical one for that region. The persistence of the cold airmass outflows from the Arctic implies, however, that a particularly large portion of the Nordic seas was affected by this CAO at a time.

\section{b. From evaporation to precipitation}

One of the salient features of polar cold air masses favorable for inducing CAOs is their initial dryness, thus leading to the strong uptake of moisture once the air mass is exposed to the ocean followed by the formation of convective clouds and precipitation. This is exemplarily illustrated by the AVHRR satellite image (Fig. 5a) valid at 1935 UTC 25 December showing cloud streets that develop off the sea ice edge, as well as a transition toward cellular convection. Furthermore, Fig. 6 shows snapshots of evaporation, total column vapor, and precipitation at 0000 UTC 26 December $(+60 \mathrm{~h})$. In the Arctic and over the Nordic seas-collocated with the CAO (purple) - total column vapor is strongly depleted with values well below $2 \mathrm{~mm}$ (Fig. 6b). It is within the $\mathrm{CAO}$, however, where the strongest evaporation rates in the study region occur (Fig. 6a). At the same time, marine precipitation collocated with the $\mathrm{CAO}$ is also prevalent (Fig. 6c). Furthermore, intense precipitation associated with orographic lifting is found along the coasts of Norway and southeastern Greenland. While a linkage between precipitation over Norway and the uptake of moisture by the CAO air mass is rather manifest, this is less obvious for precipitation along 
(a) evaporation

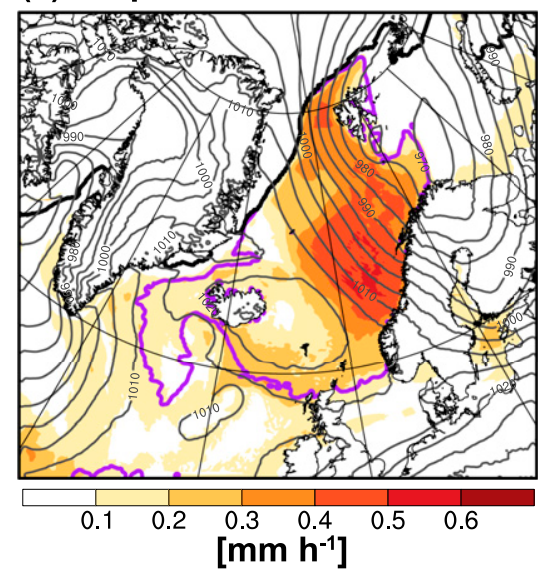

(b) total column vapour

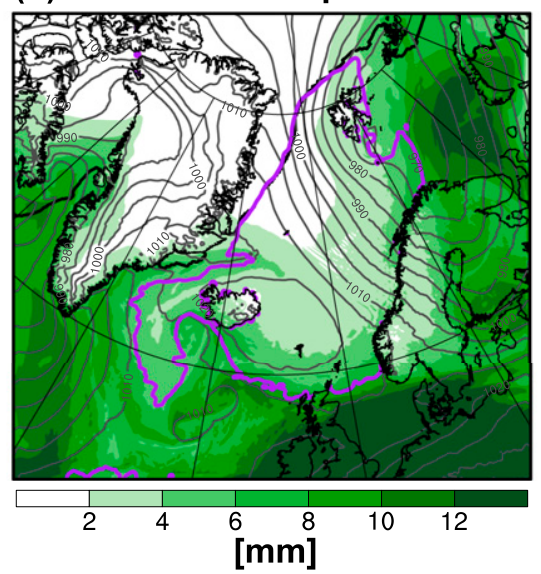

(c) precipitation

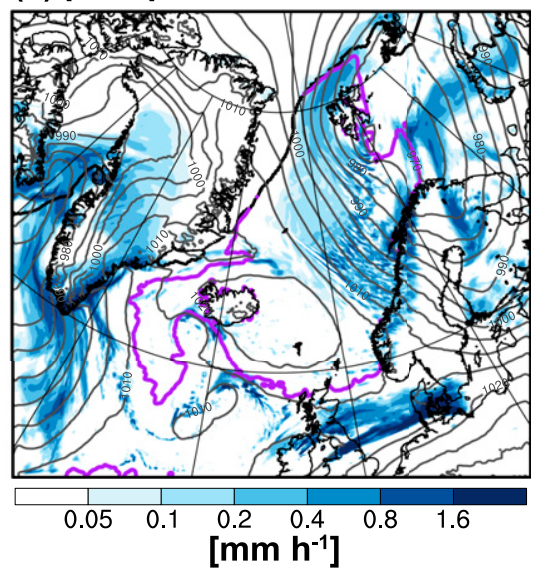

FIG. 6. Snapshots of (a) evaporation from the ocean surface, (b) total column vapor, and (c) precipitation at $0000 \mathrm{UTC} 26 \mathrm{Dec}(+60 \mathrm{~h})$. Evaporation and precipitation are averaged over the previous hour. Further shown are sea level pressure (gray, contour interval $5 \mathrm{~K}$ ), the 4-K isoline of the CAO index $\left(\theta_{\mathrm{SST}}-\theta_{900}\right.$; purple), and the sea ice edge (thick black). Data are from the $\mathrm{COSMO}_{0.05^{\circ}}$ simulation.

the southeast coast of Greenland. In the following, we will make use of the water vapor tracers as introduced in section 2 to link evaporation into the $\mathrm{CAO}$ air mass to precipitation.

First, we illustrate the evolution of the water cycle associated with the CAO throughout the previously described life cycle of the CAO. In particular, we investigate where water vapor picked up by the CAO contributes to precipitation. Figure 7 gives an overview of hourly accumulated evaporation into the CAO air mass (left column), total column tagged CAO vapor (middle column), and hourly accumulated tagged CAO precipitation (right column). The terms tagged $C A O$ vapor and tagged $C A O$ precipitation refer to the portions of water vapor and precipitation, respectively, which are associated with the CAO tracers. By definition, this represents water that has previously evaporated into the CAO air mass.

Initially, the most intense evaporation into the CAO air mass of up to $0.5 \mathrm{~mm} \mathrm{~h}^{-1}$ occurs in a narrow band off the sea ice edge and over the tongue of relatively warm waters west of Svalbard. It declines to less than $0.3 \mathrm{~mm} \mathrm{~h}^{-1}$ farther into the basin (Figs. 7a,d). Convective overturning leads to the onset of tagged CAO precipitation slightly downstream of the sea ice edge (Figs. 7c,f). As the CAO air masses are advected across the Arctic front over the warm waters of the Norwegian Sea, the evaporation rates increase again and reach values as high as near the sea ice edge. In contrast to the band along the sea ice edge, however, these high values extend much farther downstream (Figs. 7g,k). Furthermore, this increase of evaporation is concomitant with a sharp increase of tagged CAO precipitation from rather uniform values of around $0.1 \mathrm{~mm} \mathrm{~h}^{-1}$ in the Greenland
Sea to locally more than $1 \mathrm{~mm} \mathrm{~h}^{-1}$ in the Norwegian Sea (e.g., Fig. 7i). Consequently, total column tagged CAO vapor does not show such pronounced changes downstream of the Arctic front as evaporation and precipitation; instead it increases nearly linearly with distance from the sea ice edge to close to $4 \mathrm{~mm}$ near the Norwegian coast (Figs. 7e,h,l). These findings suggest a strong influence of the SST distribution on the water cycle and, in particular, a more vigorous turnover of water vapor over the warm waters of the Norwegian Sea compared to the Greenland Sea that limits the growth of column tagged CAO vapor.

Important parts of the Nordic seas are bounded by steep orographic rises. Hence, a major portion of CAO precipitation occurs over land induced by orographic lifting when CAO air masses impinge on the coast. Indeed, high rates of tagged CAO precipitation are found along the coast of central and northern Norway, but also along southeastern Greenland (Fig. 7i) with the latter being related to a southwestward excursion of tagged CAO vapor during the early phase of the CAO (Figs. 7e,h). This poses the question about what role moisture input and precipitation efficiency over the ocean play in controlling the amount of precipitation along the orographic rises.

Figure 8 shows the contributions of $\mathrm{CAO}$ and nonCAO vapor to marine precipitation in the GreenlandIceland-Norwegian (GIN) Seas and over central to northern Norway (NOR; see boxes in Fig. 1a). Colors indicate tagged $\mathrm{CAO}$ vapor released in the respective time frames and gray shadings depict tagged vapor initially present and of non-CAO origin. The contribution of tagged CAO vapor to marine precipitation in the GIN region (Fig. 8a) increases gradually from the start of the 
evaporation

(a) 201512240000 UTC

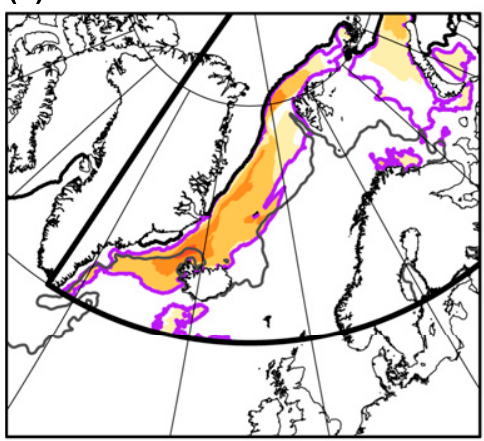

(d) 201512250000 UTC

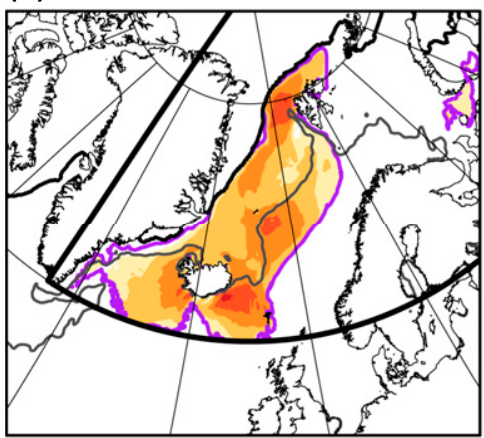

(g) 201512260000 UTC

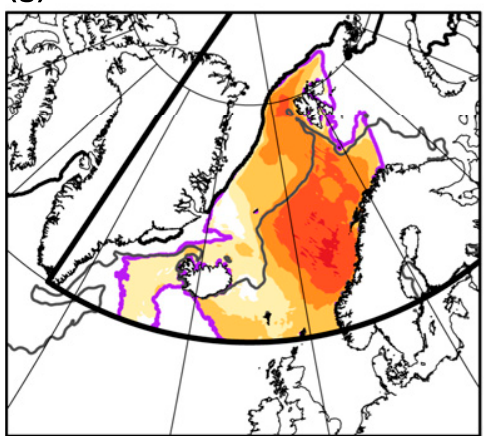

(k) 201512270000 UTC

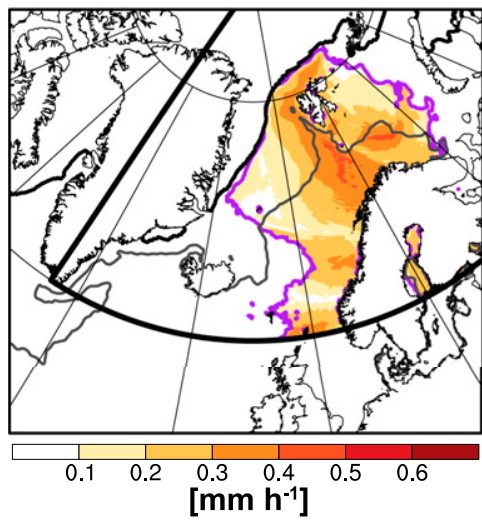

(b)

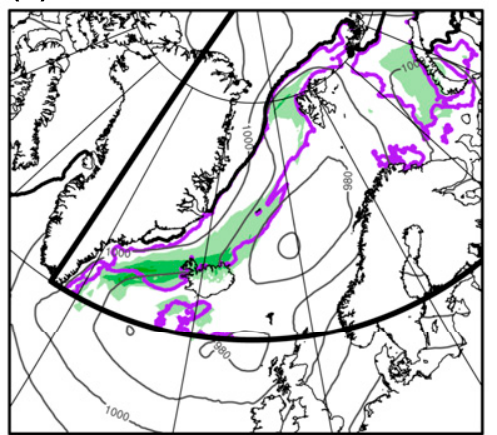

(e)

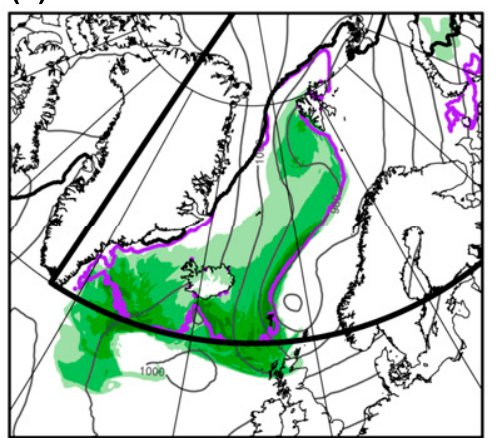

(h)

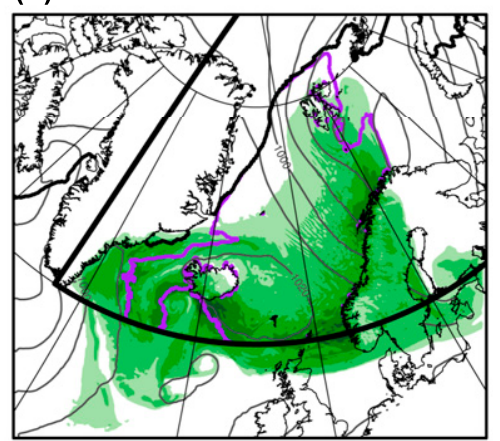

(I)

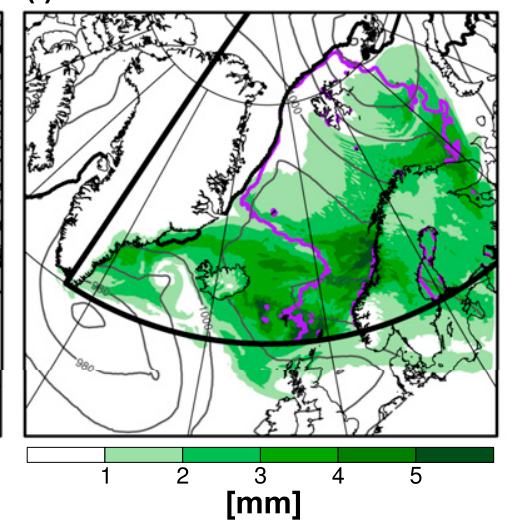

precipitation

(c)

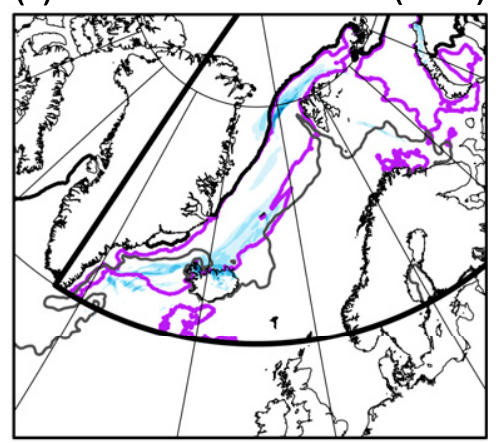

(f)

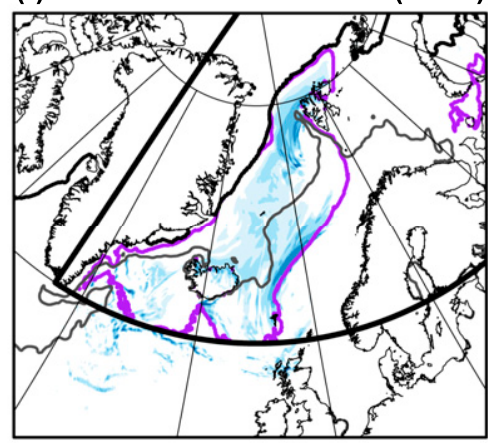

(i)

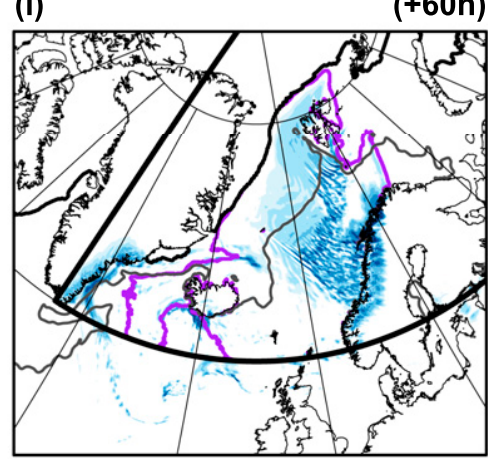

(m)

(+84h)

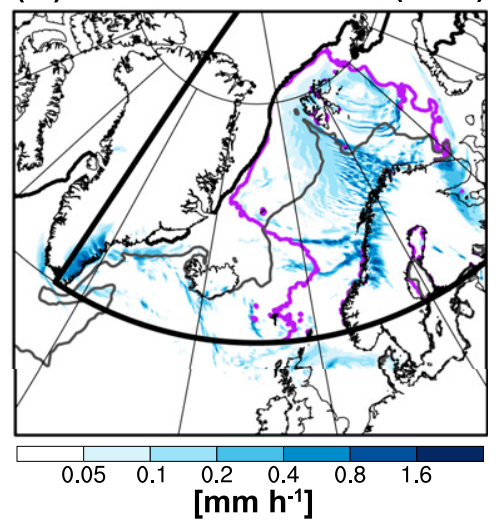

FIG. 7. Snapshots of (left) tagged evaporation into the CAO air mass, (middle) tagged CAO column vapor, and (right) tagged CAO precipitation at (a)-(c) 0000 UTC 24 Dec, (d)-(f) 0000 UTC 25 Dec, (g)-(i) 0000 UTC 26 Dec, and (k)-(m) 0000 UTC 27 Dec. Evaporation and precipitation are averages over the previous hour. Note that evaporation into the CAO air mass is tagged only poleward of $60^{\circ} \mathrm{N}$ and east of $45^{\circ} \mathrm{W}$ (cf. thick black lines). Further shown are the CAO evaporation region (purple) and the sea ice edge (black), as well as (middle) sea level pressure (gray contours in intervals of $10 \mathrm{hPa}$; omitted over land) and (left),(right) the 277-K isotherm of SST with cold waters located to the left and north of the isoline (gray line). Data are from the COSMO $0.05^{\circ}$ simulation. 
(a) GIN Seas

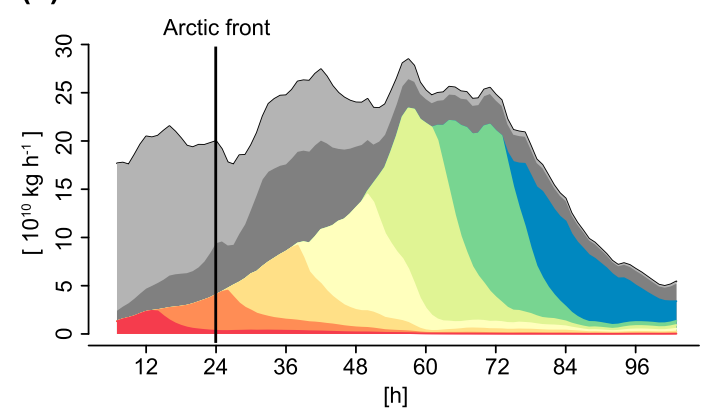

(b) Norway

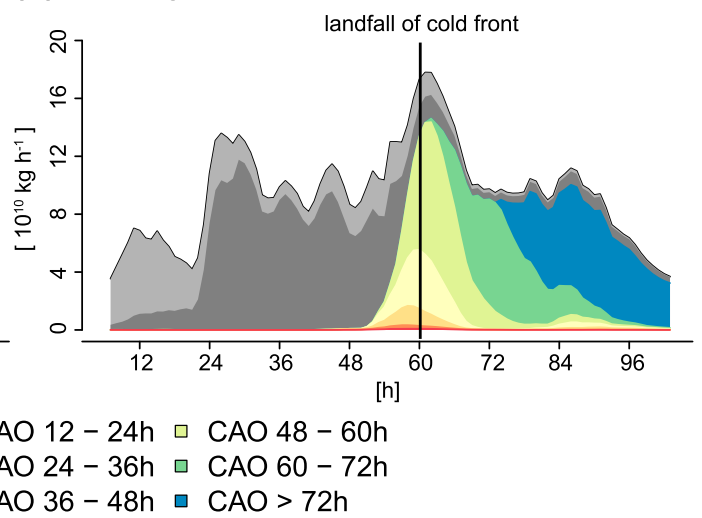

FIG. 8. Temporal evolution of tagged precipitation integrated over (a) the Greenland-Iceland-Norwegian (GIN) Seas (GIN box, Fig. 1a) and (b) Norway (NOR box, Fig. 1a) with contributions shown separately for tagged vapor initially present in the domain (light gray), entering the domain from the boundary or the surface outside of the CAO mask (dark gray), and associated with the CAO tracers that are released in 12-hourly intervals (color). Time axis is relative to the initial time of the simulation and the time when the CAO air mass reaches across the Arctic front and the cold front makes landfall are indicated in (a) and (b), respectively. Data are from the COSMO $0.05^{\circ}$ simulation.

simulation. Contributions increase as the more intense CAO precipitation downstream of the Arctic front sets in at 1200 UTC 24 December $(+24 \mathrm{~h})$. Marine CAO precipitation peaks and reaches a plateau around 0000 UTC 26 December $(+60 \mathrm{~h})$ when the cold front makes landfall along the Norwegian coast and the CAO air mass occupies most of the GIN Seas. During that plateau phase, the bulk of precipitation in the GIN region is of CAO origin $(>80 \%)$. After 1200 UTC 26 December $(+72 \mathrm{~h})$ the continuous supply of CAO air masses decreases and marine $\mathrm{CAO}$ precipitation in the GIN region declines.

CAO precipitation in the NOR region (Fig. 8b) sets in with the landfall of the cold front and peaks at 0000 UTC 26 December $(+60 \mathrm{~h})$ with the highest precipitation rates throughout the entire event. Interestingly, most of the cold frontal precipitation in the NOR box is of CAO origin, whereas precipitation of waters of non$\mathrm{CAO}$ origin in the ascent regions ahead of the front contributes substantially less. This may be related to a weakening of the front caused by the frontolytic effect of surface sensible heat fluxes (Spensberger and Sprenger 2018). After the passage of the cold front, precipitation in the NOR region levels off at a lower and fairly constant value while the CAO air mass is lifted over the orographic rise (Fig. 8b). After 0000 UTC 27 December $(+84 \mathrm{~h})$ the dome of cold air translates into the Barents Sea and precipitation decreases.

In summary, the synoptic analysis points toward a highly local water cycle with relatively rapid turnover of vapor established during the life cycle of the $\mathrm{CAO}$ over large portions of the Nordic seas. In the following section, we aim to shift the focus away from this synoptic view toward a space-time-integrated perspective on the water cycle during this $\mathrm{CAO}$ event with the goal to corroborate these qualitative findings more quantitatively.

\section{The CAO water cycle}

\section{a. Integral characteristics}

A quantitative account of the net input of vapor into the atmosphere during this CAO event is obtained from the domain-integrated evaporation into the CAO air mass and tagged CAO precipitation (Fig. 9). In this section we focus on the $0.05^{\circ} \times 0.05^{\circ}$ simulation only (solid lines). The rate of evaporation into the CAO air mass (orange) increases rapidly, peaks after 1200 UTC 25 December $(+48 \mathrm{~h})$, and declines shortly after 1200 UTC 26 December $(+72$ h, Fig. 9a). Tagged CAO precipitation (blue) peaks about $12 \mathrm{~h}$ after evaporation and reaches a plateau sustained for nearly 1 day until 0000 UTC 27 December $(+84 \mathrm{~h})$. Subsequently, precipitation largely compensates for the additional moisture input by evaporation as evident from the closeness of the orange and blue lines. Consequently, the net input of vapor remains small after that time. Initially, most of the tagged CAO precipitation is collocated with the CAO masks (cf. green and blue lines). As of 1200 UTC 25 December $(+48 \mathrm{~h})$, however, more and more of the CAO vapor is lost via precipitation in dynamical weather systems outside of the CAO and along the orographic boundaries of the Nordic seas. The total evaporation into the CAO air 

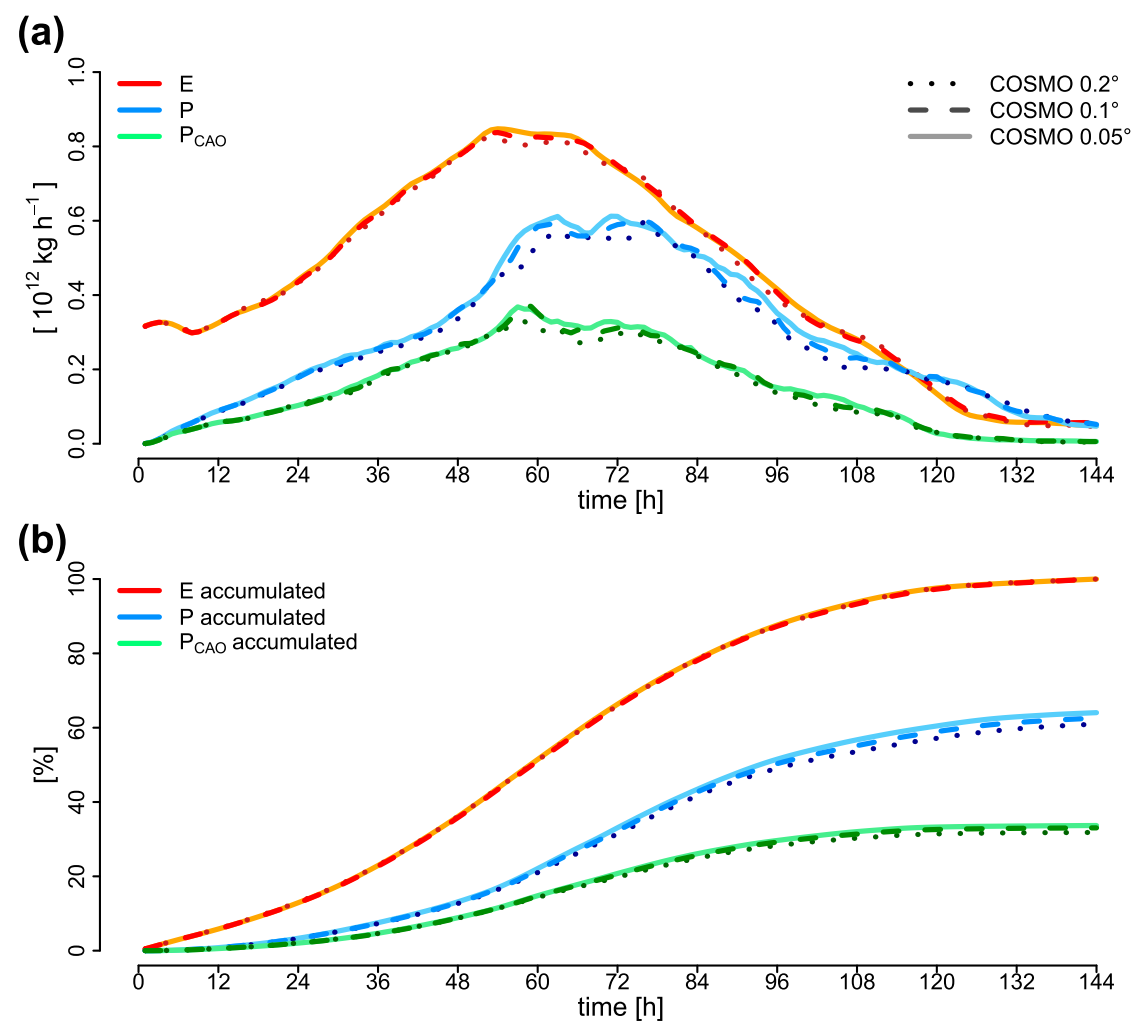

FIG. 9. Temporal evolution of domain-integrated tagged CAO water budget. (a) Rates of tagged evaporation into the $\mathrm{CAO}$ air mass (red), tagged CAO precipitation (blue), and tagged CAO precipitation collocated with the CAO mask $\left(\theta_{\mathrm{SST}}-\theta_{900}=4 \mathrm{~K}\right.$; green). (b) As in (a) but accumulated over time and expressed in \% of the total evaporation into the CAO air mass over the whole length of the simulation. All quantities are shown for the COSMO $0.2^{\circ}$ (dotted), COSMO $0.1^{\circ}$ (dashed), and COSMO $0.05^{\circ}$ (solid) simulations.

mass amounts to $65 \times 10^{12} \mathrm{~kg}$, of which $22 \times 10^{12} \mathrm{~kg}$ fall as precipitation within the CAO mask corresponding to $34 \%$ of the total uptake (Fig. $9 \mathrm{~b}$ ). Thus, the net injection of moisture by the CAO of $43 \times 10^{12} \mathrm{~kg}$ corresponds to nearly $7 \%$ of the integrated water content of the atmosphere poleward of $40^{\circ} \mathrm{N}\left(\approx 6.4 \times 10^{14} \mathrm{~kg}\right)$ as estimated from the ERA-Interim reanalysis. An additional $20 \times 10^{12} \mathrm{~kg}$ or $30 \%$ is lost via precipitation outside of the CAO.

Brümmer (1997) computed composite water budgets of 11 CAO cases based on aircraft measurements (8 CAOs from Fram Strait and 3 in the Norwegian Sea). That study estimated the efficiency of precipitation formation by the $\mathrm{CAO}$, expressed as the ratio of precipitation to evaporation, to be $25 \%$ to $33 \%$ up to $150 \mathrm{~km}$ from the sea ice edge and values in excess of $50 \%$ farther downstream. Given that the CAO investigated here extends from the sea ice edge across the entire Nordic seas and thus occupies a major portion of the warm waters in the Norwegian Sea, the value of $34 \%$ found here appears rather low in comparison, even though it has been computed from evaporation and precipitation integrated over the entire event, as well as in space. We therefore shed more light on the spatial variation of the precipitation efficiency by considering the footprints of the CAO event in accumulated evaporation and precipitation.

Evaporation into the CAO air mass accumulated over the CAO event features clear local maxima (Fig. 10a). A first prominent maximum is located along the sea ice edge extending from north of Svalbard into the Greenland Sea and with values in excess of $20 \mathrm{~mm}$. A second maximum of the same magnitude is found on the warm side of the Arctic front (gray contour). The dominant cause for the evaporation maximum over Fram Strait and in the Greenland Sea lies in the sustained nature of the off-ice flow throughout the entire event (i.e., Fig. 4) leading to less intense but more persistent instantaneous evaporation rates than in the Norwegian Sea (cf. Fig. 7). Furthermore, the existence of an ice-sea-breeze circulation could contribute further toward enhanced fluxes in the vicinity of the sea ice edge (e.g., Chechin et al. 2013). Despite the high instantaneous evaporation rates, 
(a) $\mathrm{E}$

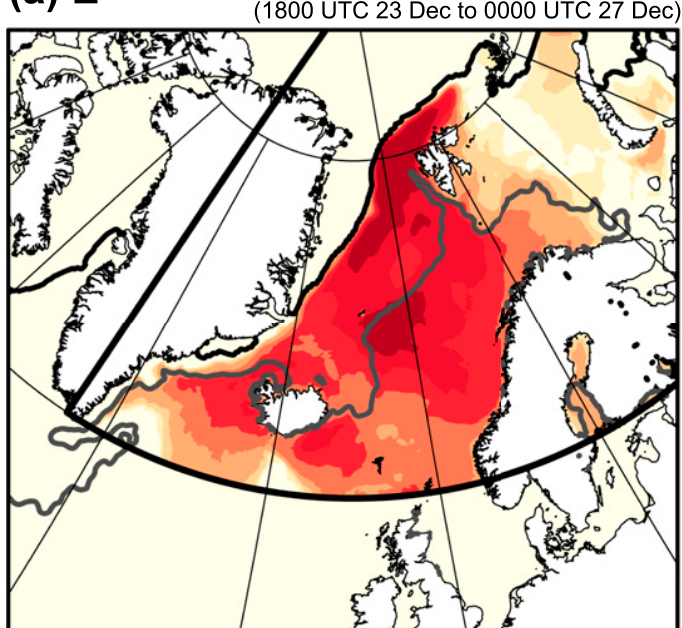

(c) E - P
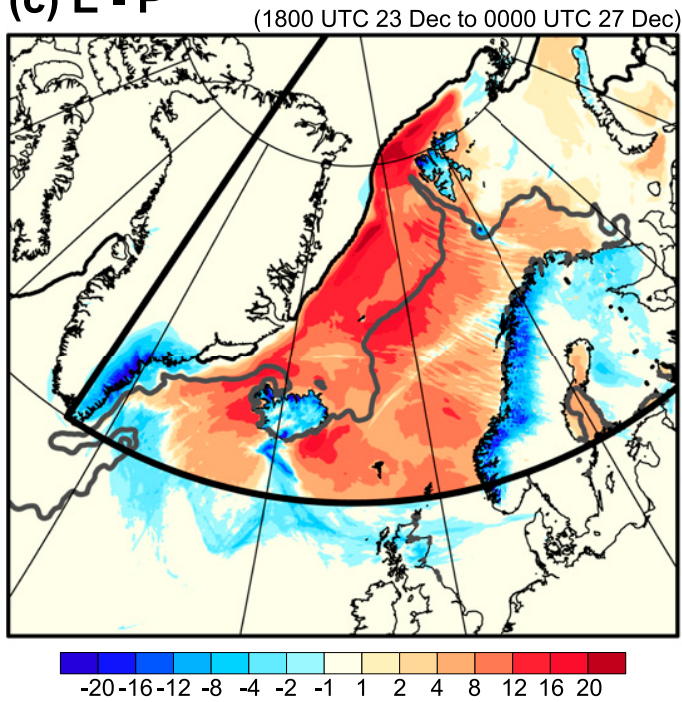

[mm] (b) $\mathbf{P}$

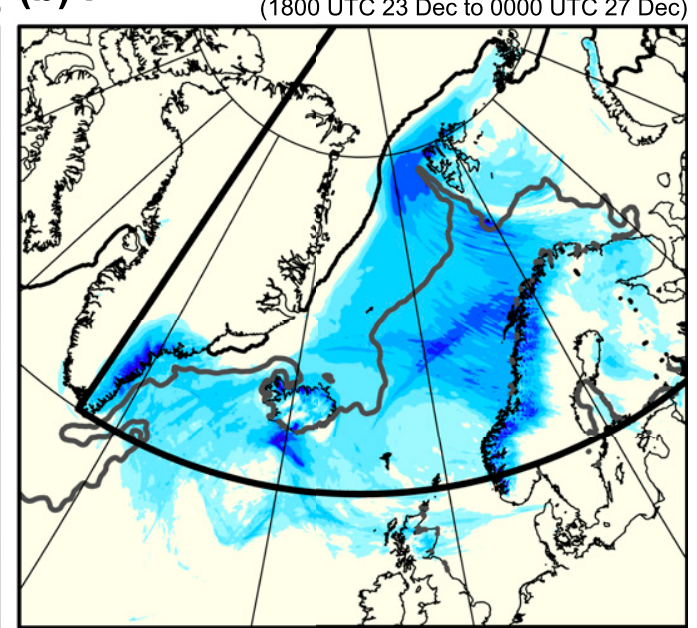

(d) $P_{\mathrm{CAO}} / \mathrm{E}$

$P_{C A O}$ and $E$ accumulated over $78 \mathrm{~h}$

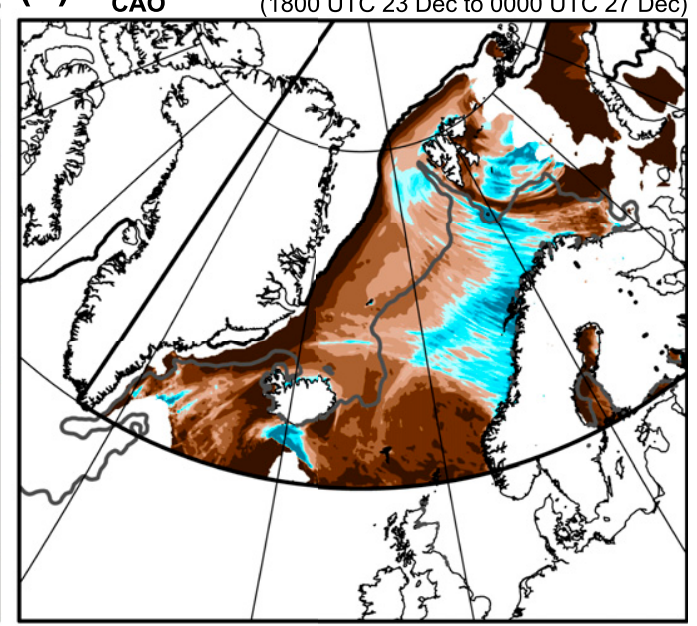

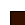

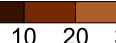

[\%]

FIG. 10. Footprints of tagged CAO (a) evaporation, (b) precipitation, (c) evaporation minus precipitation, and (d) the ratio of precipitation collocated with the CAO evaporation mask $\left(\theta_{\mathrm{SST}}-\theta_{900}=4 \mathrm{~K}\right)$ and evaporation in $\%$. Evaporation and precipitation are accumulated over $78 \mathrm{~h}$ in the interval from $1800 \mathrm{UTC} 23 \mathrm{Dec}(+6 \mathrm{~h})$ to 0000 UTC $27 \mathrm{Dec}(+84 \mathrm{~h})$. Note that the scale in (c) applies also to (a) and (b) to facilitate comparison. Regions with evaporation of less than $1 \mathrm{~mm}$ are masked out in (d). Furthermore, the 277-K isotherm of SST is drawn to illustrate the location of the Arctic front (gray line). Cold waters are located to the west and north of this line. Data are from the COSMO $0.05^{\circ}$ simulation.

the rather episodic passage of the $\mathrm{CAO}$ air mass over the Norwegian Sea (i.e., Fig. 4) leads to a decrease in the accumulated evaporation from the Arctic front toward the coast of Norway. Consequently, evaporation accumulated during the event is less over the warm waters in the Norwegian Sea than over the cold waters near the sea ice edge in the Greenland Sea.

Accumulated CAO precipitation increases downstream of the Arctic front with values of more than $12 \mathrm{~mm}$ over much of the eastern Norwegian Sea (Fig. 10b). This increase reflects the considerably stronger precipitation rates there compared to the upstream region. Similarly high values of accumulated precipitation are also found in an adjacent band inland of the west coast of Norway and in southeastern Greenland. An eminent peak in total precipitation occurs between the sea ice edge and Svalbard, where, because of the continuous passage of CAO air masses, weak but persistent precipitation leads to an accumulated precipitation of slightly more than $12 \mathrm{~mm}$. This peak is 


\section{evaporation}
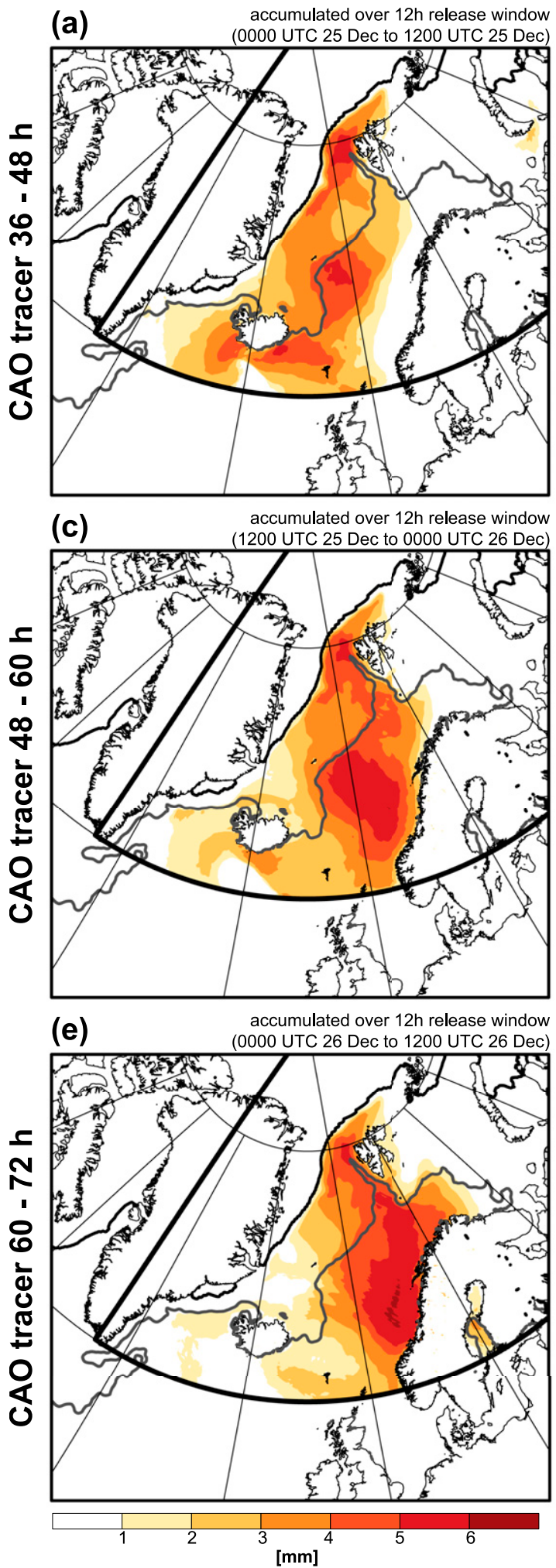

precipitation

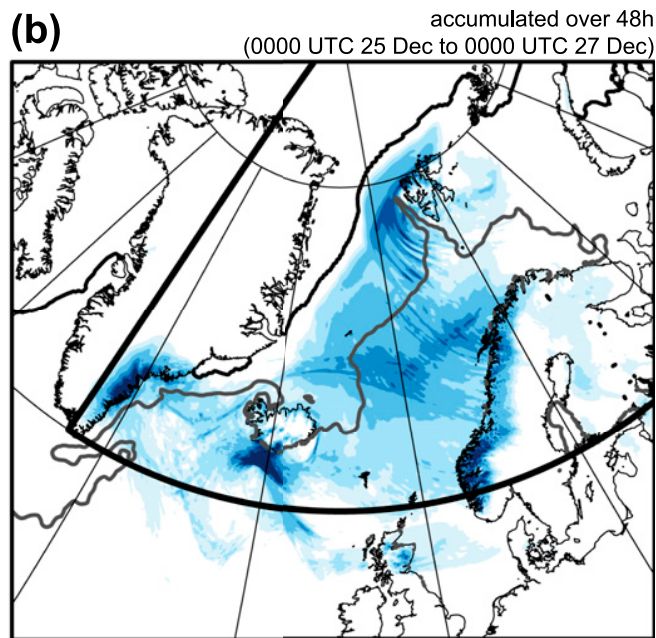

(d)
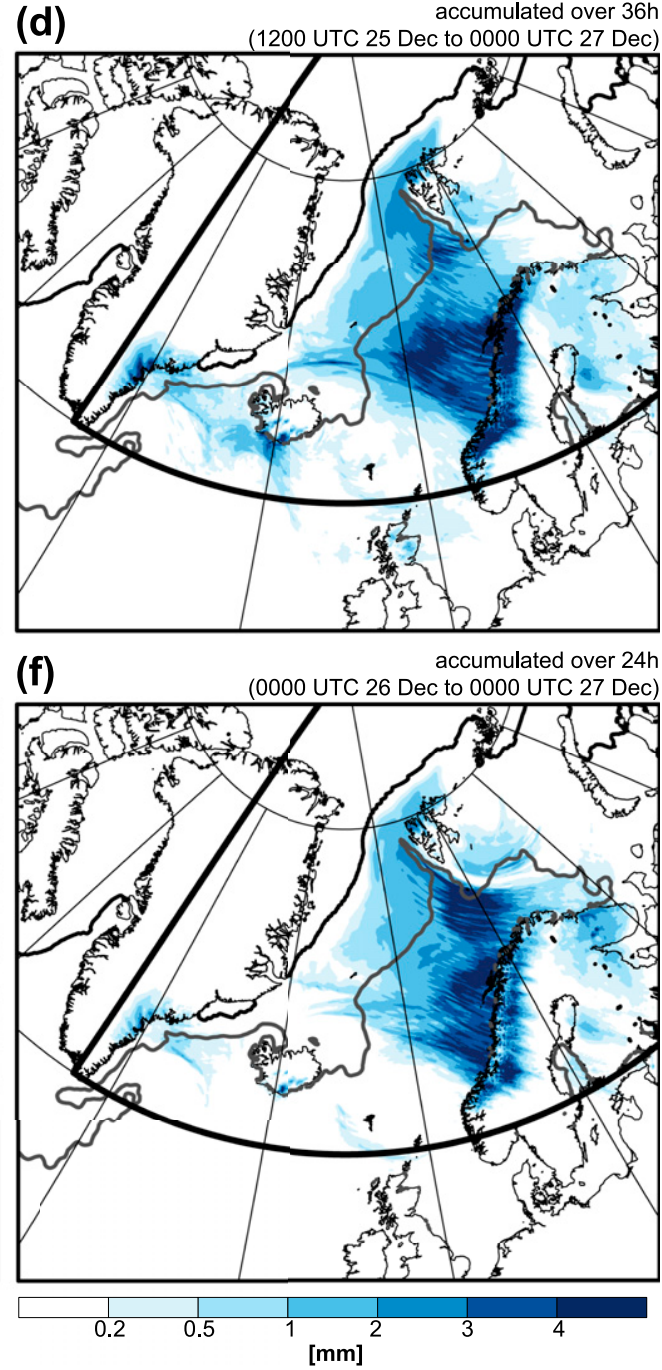

FIG. 11. Footprints of tagged CAO (left) evaporation and (right) precipitation for tracers released between (a),(b) 0000 UTC 25 Dec and 1200 UTC 25 Dec (36-48 h); (c),(d) 1200 UTC 25 Dec and 0000 UTC 26 Dec 
shifted slightly downstream of the evaporation maximum near the sea ice edge.

We obtain the footprint of the CAO in net freshwater fluxes, defined as evaporation minus precipitation, by combining accumulated evaporation and precipitation. The largest positive values of the freshwater flux associated with the CAO, thus, ensue near the sea ice edge northwest of Svalbard and in the Greenland Sea, as well as on the warm side of the Arctic front (Fig. 10c). The freshwater flux declines considerably downstream of these maxima as precipitation strengthens such that over the eastern part of the Norwegian Sea it reaches nearly neutral or even slightly negative values. It therefore seems that precipitation from water picked up by the CAO earlier and farther upstream to a large degree compensates for the strong evaporation rates over the warm waters in the Norwegian Sea.

The efficiency of precipitation formation (the ratio of precipitation falling in collocation with the $\mathrm{CAO}$ mask and evaporation into the CAO air mass) has the lowest values of less than $10 \%$ near the sea ice edge, while steadily increasing downstream with values in the eastern Norwegian Sea largely exceeding 50\% (Fig. 10d). The ratio of $34 \%$ obtained previously from area-integrated quantities is, therefore, representative of the values near the Arctic front in the middle of the basin. Between the sea ice edge and Svalbard there is another region with ratios larger than $50 \%$, which occurs as a result of the large amount of CAO precipitation. Since this is the region where 8 of the 11 CAOs described in Brümmer (1997) occurred, it is likely that the values derived from their composite water budget are representative of this particular region. In fact, our estimates are in good agreement with the increase of the ratio from 0.25 near the sea ice edge northwest of Svalbard to 0.6 about $300 \mathrm{~km}$ downstream as found by Brümmer (1997). On the scale of the Nordic seas, however, the ratio increases less rapidly with distance from the sea ice edge. We suggest that this effect is owed to the large SST gradient related to the Arctic front and the associated increase of the evaporation rates.

\section{b. Local nature of the water cycle and rapid overturning}

The local nature of the water cycle is emphasized by the spatial footprints of accumulated evaporation and precipitation of the individual CAO tracers that are released in 12-hourly intervals. Figure 11 depicts these footprints for the three tracers that contribute most to precipitation in the GIN and NOR regions until 0000 UTC 27 December $(+84 \mathrm{~h})$, namely, the tracers that are released 36-48, 48-60, and 60-72 h (see Fig. 8). Evaporation is accumulated over the 12-hourly window during which the tracer is released, while precipitation is accumulated from the start of the tracer release window until 0000 UTC 27 December. The accumulated evaporation in the Greenland Sea reaches values of $5 \mathrm{~mm}$ between the sea ice edge and Svalbard, and is quite similar for all three tracers.

Major differences exist, however, downstream of the Arctic front in the Norwegian Sea. Moisture uptake by the tracer released between 36 and $48 \mathrm{~h}$ is confined to the region west of the position of the cold front at the end of the tracer release window (1200 UTC 25 December, Fig. 11a), such that the eastern Norwegian Sea does not contribute. Accumulated precipitation of 1-3 mm, in contrast, extends farther downstream over the entire Norwegian Sea and spreads along the coast of Norway (Fig. 11b). This is a hallmark of the accumulation of CAO vapor on the rearward side of the cold front vapor that contributes to frontal precipitation when the front weakens while passing the eastern Norwegian Sea.

The water cycle associated with the two subsequently released tracers appears more spatially confined. The accumulated evaporation increases rapidly downstream of the Arctic front and reaches 5-6 mm in most of the Norwegian Sea (Figs. 11c,e). Furthermore, there is a pronounced increase of precipitation to values of more than $4 \mathrm{~mm}$ over a widespread area in the Norwegian Sea with maxima displaced slightly to the east of maxima in evaporation (Figs. 11d,f). The spatially confined patterns in accumulated evaporation and precipitation, in particular the closeness of local maxima in evaporation and precipitation, clearly point toward a highly localized nature of the water cycle, and consequently a rapid overturning of moisture.

The intensity and speed of the overturning of moisture within the $\mathrm{CAO}$ air mass is substantiated by the short residence time of the vapor in the atmosphere (i.e., the time between evaporation and precipitation). Figure 12 shows the distribution of the residence time as estimated from the CAO tracers released in

(48-60 h); and (e),(f) 0000 UTC 26 Dec and 1200 UTC 26 Dec $(60-72 \mathrm{~h})$ in the $0.05^{\circ} \times 0.05^{\circ}$ simulation. Evaporation is accumulated over the respective release window of each tracer, and precipitation is accumulated from the start of the release window until 0000 UTC 27 Dec. The $277-\mathrm{K}$ isotherm of SST is drawn to illustrate the location of the Arctic front (gray line). Cold waters are located to the west and north of this line. Data are from the COSMO $0.05^{\circ}$ simulation. 
(a) Greenland, Iceland and Norwegian Seas

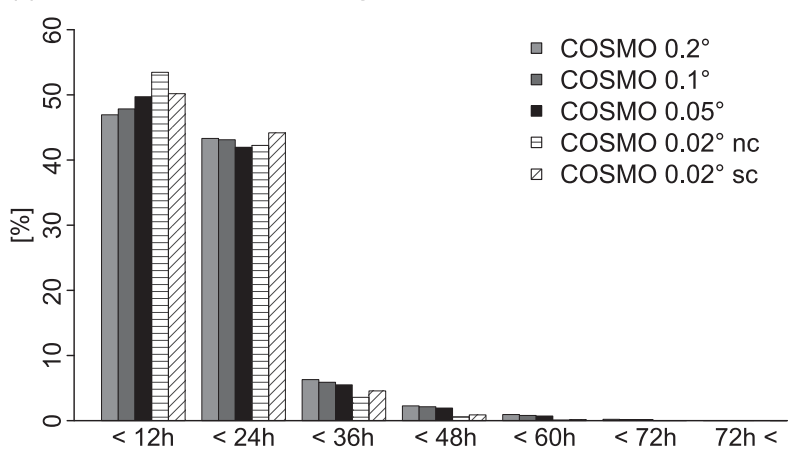

(b) Norway

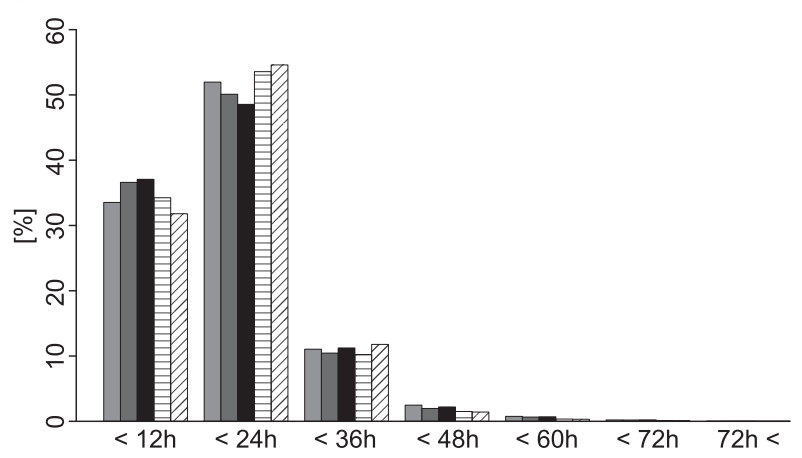

FIG. 12. Residence time of waters in tagged CAO precipitation expressed as fractions of total CAO precipitation from 1800 UTC 23 Dec $(+6 \mathrm{~h})$ to 0000 UTC $27 \operatorname{Dec}(+84 \mathrm{~h})$ (a) in the GreenlandIceland-Norwegian (GIN) Seas (GIN box, Fig. 1a) and (b) over Norway (NOR box, Fig. 1a) for simulations (from left to right) at resolutions of $0.2^{\circ} \times 0.2^{\circ}, 0.1^{\circ} \times 0.1^{\circ}, 0.05^{\circ} \times 0.05^{\circ}$, and $0.02^{\circ} \times 0.02^{\circ}$, the latter both for simulations without (nc) and with (sc) shallow convection scheme active. Note that these estimates represent upper limits for the residence time (cf. section 2).

12-hourly intervals (see section 2). Note that the 12hourly bins for the residence time are exclusive (i.e., all CAO precipitation in one of the boxes is attributed to exactly one bin). Because of the 12-hourly intervals between the release of new tracers, some of the precipitation with a residence time of, for example, less than $24 \mathrm{~h}$ may in fact have evaporated less than $12 \mathrm{~h}$ ago. This estimate, therefore, presents an upper limit for the residence time. Figure 12 a shows that more than $45 \%$ of the CAO precipitation in the GIN region has evaporated less than $12 \mathrm{~h}$ before, and another about $40 \%$ less than $24 \mathrm{~h}$ before with a sharp drop in the contributing fraction for residence times larger than one day. This sharp drop for residence times larger than one day is also present in CAO precipitation over Norway, though with a shift toward higher residence times (Fig. 12b). The largest contribution of nearly $50 \%$ is from the category with evaporation less than $24 \mathrm{~h}$ ago, and about $35 \%$ for 12 -h residence time. As the cold front makes landfall with pronounced precipitation, it deposits water that evaporated in the early phase of the CAO and accumulated on the rearward side of the front, contributing to the observed shift in residence times. Given that these estimates present upper limits, we conclude that the mean residence time of precipitating $\mathrm{CAO}$ waters is clearly below $24 \mathrm{~h}$. The water cycle associated with CAOs is, therefore, highly localized and characterized by very rapid overturning on a time scale of less than a day.

\section{Sensitivity to model resolution}

As previous modeling studies of the convective boundary layer of CAOs with horizontal grid spacings in the convective gray zone (i.e., a few kilometers) have shown, substantial differences in the boundary layer evolution may arise in simulations with different model resolutions because of a lack of scale awareness of the parameterizations for convection and turbulent mixing (e.g., Field et al. 2017; Tomassini et al. 2017). Such deficiencies may also impact the representation of the hydrological cycle. We therefore assess the robustness of the previously identified integral characteristics of the hydrological cycle of the CAO, as well as its footprint in freshwater fluxes, using model simulations at grid spacings spanning the range from $0.2^{\circ} \times 0.2^{\circ}$ to convection permitting $0.02^{\circ} \times 0.02^{\circ}$.

First, we compare the domain-integrated hydrological cycle of the three coarsest simulations (Fig. 9). As reflected in evaporation into the CAO air mass and CAO precipitation, there is a close agreement between the reference simulation $\left(0.05^{\circ} \times 0.05^{\circ}\right.$, solid $)$ and the two simulations with larger grid spacing $\left(0.1^{\circ} \times 0.1^{\circ}\right.$ and $0.2^{\circ} \times 0.2^{\circ}$, dashed and dotted, respectively). While the total amount of evaporation by the CAO is nearly identical for all simulations (differences of less than $1.2 \%$ between the simulations with grid spacings of $0.2^{\circ} \times 0.2^{\circ}$ and $0.05^{\circ} \times 0.05^{\circ}$ ), the total amount of CAO precipitation increases by about $6 \%$ as the grid spacing decreases. As also supported by the slightly lower residence times, this indicates a modestly more rapid turnover of CAO vapor at lower grid spacings (cf. Fig. 12).

Second, we consider in Fig. 13 the spatial imprints in 78-h accumulated freshwater fluxes as in Fig. 10c. The spatial patterns are consistently simulated in terms of location and shape of the spatial structure along the sea ice edge west of Svalbard and in the Greenland Sea. Simulations also agree regarding the location of the local maximum on the warm side of the Arctic front. Clear differences in magnitude are, however, apparent downstream of the Arctic front, especially along the coast and over Norway, and in the finer-scale structures. 
(a) COSMO $0.2^{\circ}$

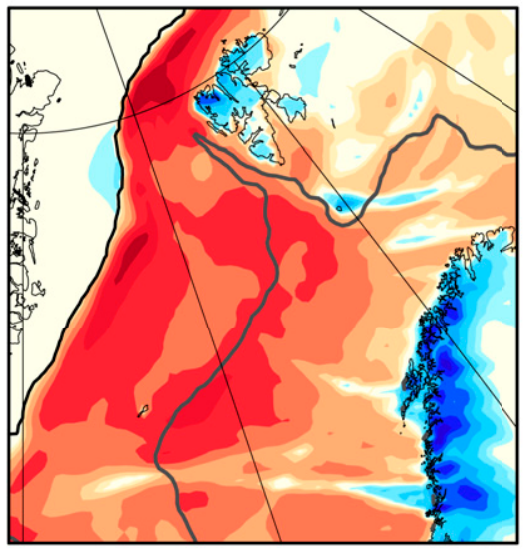

(c) COSMO $0.05^{\circ}$

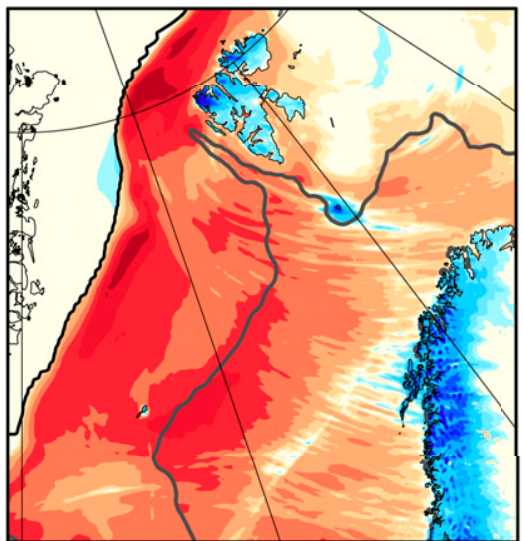

(b) COSMO $0.1^{\circ}$

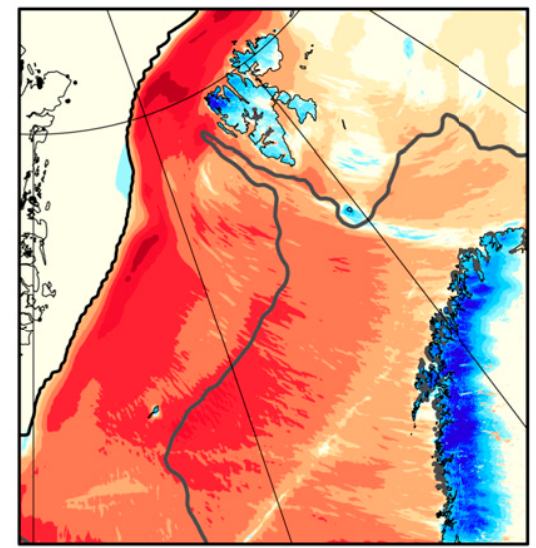

(d) COSMO $0.02^{\circ} \mathrm{nc}$

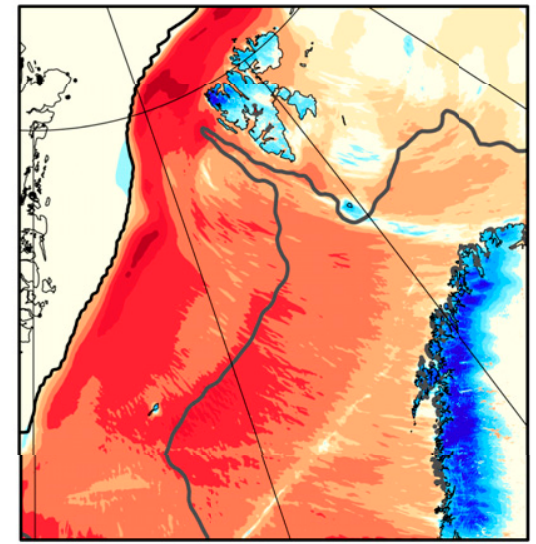

(e) COSMO $0.02^{\circ} \mathrm{sc}$

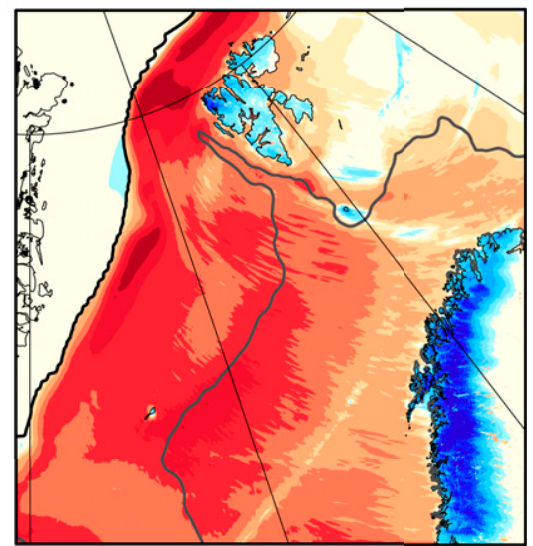

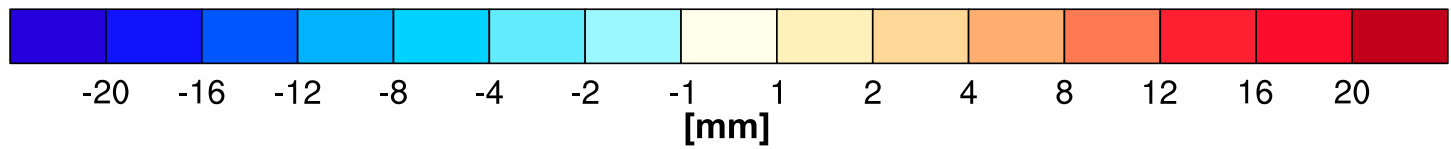

FIG. 13. Footprints of tagged CAO evaporation minus precipitation for simulations at resolutions of (a) $0.2^{\circ} \times 0.2^{\circ},(\mathrm{b}) 0.1^{\circ} \times 0.1^{\circ}$, (c) $0.05^{\circ} \times 0.05^{\circ}$, and (d),(e) $0.02^{\circ} \times 0.02^{\circ}$ without (nc) and with (sc) shallow convection scheme active, respectively. Fields are accumulated over the 78-h period between 1800 UTC $23 \mathrm{Dec}(+6 \mathrm{~h})$ and 0000 UTC $27 \mathrm{Dec}(+84 \mathrm{~h})$. To facilitate comparison, all fields are shown for the nested domain of the simulations at $0.02^{\circ} \times 0.02^{\circ}$ resolution. The $277-\mathrm{K}$ isotherm of SST is drawn to illustrate the location of the Arctic front (gray line). Cold waters are located to the west and north of this line.

Spatial integrals of the accumulated precipitation associated with each of the individual tracers over the GIN region (GIN box in Fig. 1a; Fig. 14a) and central to northern Norway (NOR box Fig. 1a; Fig. 14b) show that marine CAO precipitation increases as grid spacing is reduced from $0.2^{\circ} \times 0.2^{\circ}$ to $0.05^{\circ} \times 0.05^{\circ}$. This increase is mainly due to the tracers that were released between 48-60 and 60-72 h. Equal contributions across resolution are observed for tracers released earlier, which, in particular, contribute to precipitation immediately behind the cold front (Fig. 14a). Thus, the differences arise mainly within the convective interior of the CAO air mass, hinting at potential inconsistencies in the interplay between the convection parameterization and the increasing portion of convective motions within the CAO air mass that are explicitly resolved by the model (e.g., Field et al. 2017; Tomassini et al. 2017).

Analysis of the separate contributions of gridscale and convective precipitation lends further support to this interpretation (Table 2): the contribution of convective precipitation increases, while gridscale precipitation reduces slightly. Since the decrease of gridscale precipitation is lower than the increase of convective precipitation, it results in a net increase of CAO precipitation. In comparison to the simulation at a grid spacing of $0.2^{\circ} \times 0.2^{\circ}$, convective precipitation nearly quadruples in the $0.05^{\circ} \times 0.05^{\circ}$ run, while gridscale precipitation reduces by less than $30 \%$ of the increase in 
a) GIN Seas

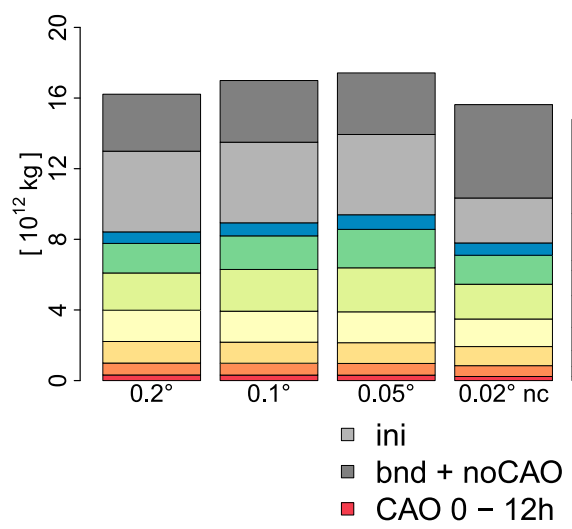

\section{b) Norway}

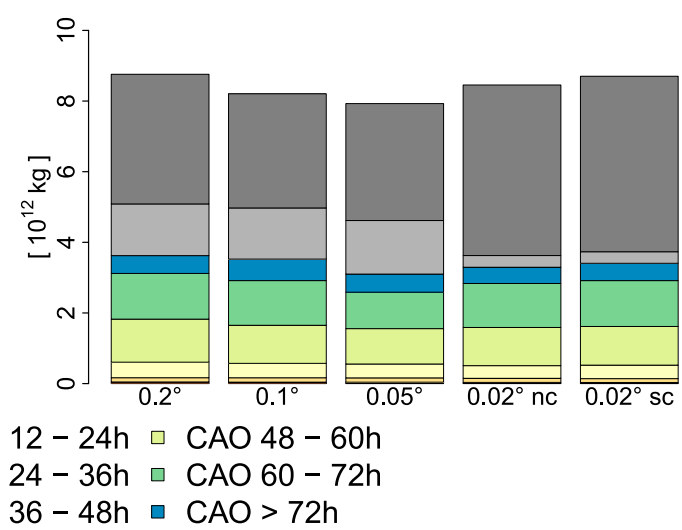

FIG. 14. Accumulated tagged precipitation integrated over (a) the Greenland-Iceland-Norwegian (GIN) Seas (GIN box, Fig. 1a) and (b) Norway (NOR box, Fig. 1a) for simulations (from left to right) at $0.2^{\circ} \times 0.2^{\circ}, 0.1^{\circ} \times 0.1^{\circ}$, $0.05^{\circ} \times 0.05^{\circ}$, and $0.02^{\circ} \times 0.02^{\circ}$ resolution without $(\mathrm{nc})$ and with $(\mathrm{sc})$ shallow convection scheme active. The accumulation is from 1800 UTC 23 Dec $(+6 \mathrm{~h})$ until 0000 UTC $27 \mathrm{Dec}(+84 \mathrm{~h})$. Contributions are shown separately for initial vapor (light gray), vapor entering the domain from the boundary or the surface outside of the CAO mask (dark gray), and vapor of CAO origin released in 12-hourly intervals (color).

convective precipitation. Since the evaporation rates are nearly identical in all three simulations (Fig. 12), an important implication of the increase of marine CAO precipitation with increasing resolution is that there is less CAO vapor available that could contribute to precipitation over Norway (Fig. 14b).

The two convection permitting simulations with a grid spacing of $0.02^{\circ} \times 0.02^{\circ}$ show a clear decrease in CAO precipitation in the GIN region (Fig. 14a), and further an increase over Norway (Fig. 14b) when compared to the $0.05^{\circ} \times 0.05^{\circ}$ simulation. Marine CAO precipitation decreases more strongly in the simulation with shallow convection parameterization switched on. The parameterization acts to transport CAO vapor upward and potentially warmer air downward, and thereby leads to a modestly more rapid growth of the depth of the CAO boundary layer. This results in slightly enhanced evaporation from the ocean surface and overall less marine CAO precipitation (not shown).

Comparing outgoing longwave radiation at 1900 UTC 25 December from the two convection permitting simulations with infrared satellite imagery reveals remarkable agreement in certain details, but also emphasizes discrepancies especially downstream in the Norwegian Sea (Fig. 5). In both simulations cloud streets develop off the ice and there is a clear-cut transition from roll vortices toward cellular convection (Figs. 5b,c), in good agreement with the satellite image (Fig. 5a). Morphology and organization of the cellular convection are, however, different in the two simulations. Cloud cover is considerably less dense in the simulation without shallow convection parameterization, in agreement with the weaker net water uptake in that simulation. Furthermore, a comparison with the satellite image (Fig. 5a) suggests that the ratio between cloud free versus cloudy regions may lie somewhere in between the two simulations, albeit with clearly finer cloud structures than produced by either of them.

Based on the above analysis, we conclude that the major characteristics of the water cycle associated with the CAO are robust with respect to changes to the grid spacing. Nevertheless, quantitative inconsistencies in the representation of the $\mathrm{CAO}$ water cycle are identified even at convection permitting grid spacing, and convergence is not evident as more and more of the convective motions are resolved with decreasing grid spacing. This is consistent with large eddy simulations indicating

TABLE 2. Accumulated marine CAO precipitation area integrated over the Greenland-Iceland-Norwegian (GIN) Seas (cf. GIN box Fig. 1a) for all CAO tracers, and separately for the two tracers released between $48-60$ and $60-72 \mathrm{~h}$, respectively, for simulations at $0.2^{\circ} \times 0.2^{\circ}$ to $0.05^{\circ} \times 0.05^{\circ}$ resolution. The period of accumulation is 1800 UTC 23 Dec-0000 UTC 27 Dec and the contributions are separated into gridscale and convective precipitation. The integrated precipitation is expressed in units of $10^{12} \mathrm{~kg}$.

\begin{tabular}{clccc}
\hline \hline & & $0.2^{\circ} \times 0.2^{\circ}$ & $0.1^{\circ} \times 0.1^{\circ}$ & $0.05^{\circ} \times 0.05^{\circ}$ \\
\hline CAO all & Grid scale & 7.62 & 7.58 & 6.86 \\
tracers & Convective & 0.80 & 1.36 & 2.53 \\
CAO tracer & Grid scale & 1.83 & 1.81 & 1.51 \\
48-60 h & Convective & 0.27 & 0.55 & 0.98 \\
CAO tracer & Grid scale & 1.44 & 1.46 & 1.26 \\
$60-72 \mathrm{~h}$ & Convective & 0.23 & 0.44 & 0.92 \\
\hline
\end{tabular}


that a grid spacing on the order of $100 \mathrm{~m}$ is required to properly resolve the full spectrum of convective motions (Bryan et al. 2003) and it underlines the need for scaleaware parameterizations of the nonresolved portions of convective and subgrid-scale turbulent motions to properly represent CAOs in kilometer-scale models.

\section{Conclusions}

This study presents the dynamical evolution of an intense and long-lived yet typical CAO from Fram Strait into the Nordic seas that occurred during 24-27 December 2015. The analysis is focused on an investigation of the associated evolution and characteristics of the water cycle in the Nordic seas established during that event.

The formation and development of the CAO were closely linked to the evolution and propagation of an upper-level feature characterized by a low-lying tropopause that wandered from northwestern Greenland toward Fram Strait and from there into the Nordic seas with a dome of cold air underneath. Delimited by an initially intense cold front extending all the way to the tropopause, cold air was continuously supplied from the interior Arctic for more than two days and advected across the Nordic seas. This sustained flow of originally cold and dry air masses across the Nordic seas gave rise to intense sensible and latent heat fluxes from the ocean surface, leading to the strong transformation of the air mass.

To quantitatively analyze the characteristics of the water cycle during that $\mathrm{CAO}$, the event was investigated by means of a tracer-enabled limited-area numerical weather prediction model. Our main findings regarding the characteristics of the water cycle associated with this $\mathrm{CAO}$ event are as follows:

1) The CAO is associated with a highly confined water cycle, with a rapid overturning of vapor within the $\mathrm{CAO}$ air mass. This is underlined by the finding that the Norwegian Sea is the dominant moisture source region for CAO precipitation along the Norwegian coast and over Norway during the CAO period. During such weather situations, the Nordic seas and the surrounding topography can, thus, be considered as a natural laboratory to study the local characteristics of the water cycle by models and observations.

2) Water vapor has a very rapid turnover within the $\mathrm{CAO}$, with an average residence time of about one day. This residence time is considerably smaller than the climatological residence time of 3-4 days for vapor contributing to precipitation in the Nordic seas as obtained from trajectory analysis (Läderach and Sodemann 2016), or than the 8-10 days often considered as a global average value (e.g., Bosilovich et al. 2005).

3) About one-third of the total moisture taken up by the CAO falls as precipitation because of convective overturning in the marine CAO boundary layer. Another third rains out inside the model domain but unrelated to convection within the CAO, that is, along the steep coastal boundaries of the Nordic seas, as well as in dynamical weather systems over ocean. The last third remains as vapor in the atmosphere or is advected out of the domain. In total, this leads to a net injection of vapor by the $\mathrm{CAO}^{1}$ into the highlatitude atmosphere of $43 \times 10^{12} \mathrm{~kg}(\sim 7 \%$ of the atmospheric water content poleward of $\left.40^{\circ} \mathrm{N}\right)$.

4) The water cycle is strongly modulated by the pattern of SST over the CAO region. The CAO air mass is exposed to rapidly increasing SST as it crosses the Arctic front from the cold Greenland Sea into the warm Norwegian Sea. Consequently, evaporation rates increase substantially on the warm side of the front, as does precipitation efficiency farther downstream.

5) Accumulated freshwater fluxes are characterized by an excess of evaporation over precipitation. Overall values decrease from the ice edge toward the Norwegian coast, albeit with local maxima of the net vapor injection along the sea ice edge and on the warm side of the Arctic front. Important factors in shaping these spatial patterns are as follows:

(i) the persistent outflow of very cold air masses from Fram Strait across the ice edge for several days with moderate evaporation rates contrasting the rather episodic passage of the CAO air masses across the Norwegian Sea where evaporation rates are substantially higher,

(ii) and the partial compensation of the more intense evaporation downstream of the Arctic front in the Norwegian Sea by enhanced precipitation of CAO vapor that was picked up upstream.

6) Simulations with horizontal grid spacings ranging from $0.2^{\circ} \times 0.2^{\circ}$ to convection permitting $0.02^{\circ} \times$ $0.02^{\circ}$ indicate that the integral characteristics of the $\mathrm{CAO}$ water cycle, as well as the principal features of the CAO in footprints of freshwater fluxes are robustly represented across resolutions. Inconsistencies exist, however, regarding the amount of marine convective precipitation. Since local small-scale processes play a dominant role for the water cycle during CAO situations, CAOs can serve as ideal target cases to

\footnotetext{
${ }^{1}$ The net injection is considered to be the total evaporation into the $\mathrm{CAO}$ air mass minus precipitation caused by convective overturning within the $\mathrm{CAO}$ boundary layer.
} 
evaluate the accuracy of the representation of the water cycle and the impact of parameterized smallscale processes on the performance of numerical weather prediction models.

The characteristics of the water cycle during episodes of CAO precipitation along the Norwegian coast and over Norway are in sharp contrast to those during episodes of precipitation associated with strongly ascending moist airstreams (i.e., warm conveyor belts; Sodemann and Stohl 2013; Pfahl et al. 2014). Both types of episodes are closely linked to the passage of cyclones: warm conveyor belts are related to the warm sector of cyclones with long-range vapor transport ahead of the cold front (Madonna et al. 2014; Pfahl et al. 2014) and they often represent a major sink for vapor associated with an atmospheric river (Sodemann and Stohl 2013), whereas CAOs-as in the present case-are linked to the cyclone's cold sector (Papritz et al. 2015; Vannière et al. 2016; Papritz and Grams 2018). During periods with the frequent passage of cyclones, precipitation in the Norwegian Sea and over Norway is therefore characterized by temporally highly variable moisture source regions and associated uptake conditions, moisture transport, and time scale from evaporation to precipitation.

The insights gained from this study are also relevant for the ongoing Year of Polar Prediction (YOPP) ${ }^{2}$ effort that brings major attention to this region in terms of modeling and observational studies. The highly local water cycle in the Norwegian Sea recommends the region as a natural laboratory of the water cycle. Testing the representation of different subgrid-scale processes, including convection, in a model framework should be highly effective during such CAO situations. In addition, observational studies targeting the water cycle may be particularly valuable in this region. The distinct transformation of the CAO air masses resulting from strong latent heat fluxes create situations where natural tracers of moisture source and transport based on the stable isotope composition of the water vapor can be applied to validate the water cycle in models. Variations in the parameter deuterium excess, for example, may allow one to identify the timing and change in source conditions at coastal measurement sites (Pfahl and Sodemann 2014; Steen-Larsen et al. 2015). Such a comparison requires information on the water cycle in the model that is adequate for evaluation with isotope measurements. The tagging approach, and its extension into a full stable isotope fractionation physics package (Pfahl and Wernli 2012), allows quantification of the contributions from

\footnotetext{
${ }^{2} \mathrm{http}: / /$ www.polarprediction.net/.
}

different source regions of CAO precipitation, and to disentangle the role different processes play in the water cycle. Thus, novel observational approaches combined with powerful model diagnostics can be invaluable for evaluating and improving the representation of CAOs in models. More fundamentally, they can be a cornerstone for advancing our understanding of the role of CAOs in the high-latitude climate system.

Acknowledgments. The authors thank Rebecca Guggerli (Université de Fribourg), Stephan Pfahl (FU Berlin), and Fransziska Aemisegger (ETH Zürich) for help with the tagging implementation and for helpful discussions, as well as two anonymous reviewers for their thoughtful comments that helped to improve the manuscript. LP acknowledges support by the Swiss National Science Foundation (SNSF), Grant P300P2_174307. HS acknowledges support by the Norwegian Research Council (NFR) Projects SNOWPACE (Grant 262710) and ALERTNESS (Grant 280573).

\section{REFERENCES}

Azad, R., and A. Sorteberg, 2017: Extreme daily precipitation in coastal western Norway and the link to atmospheric rivers. J. Geophys. Res. Atmos., 122, 2080-2095, https://oi.org/10.1002/ 2016JD025615.

Baldauf, M., A. Seifert, J. Förstner, D. Majewski, M. Raschendorfer, and T. Reinhardt, 2011: Operational convective-scale numerical weather prediction with the COSMO model: Description and sensitivities. Mon. Wea. Rev., 139, 3887-3905, https://doi.org/ 10.1175/MWR-D-10-05013.1.

Bosilovich, M. G., and S. D. Schubert, 2002: Water vapour tracers as diagnostics of the regional hydrologic cycle. J. Hydrometeor., $\mathbf{3}$, 149-165, https://doi.org/10.1175/1525-7541(2002)003<0149: WVTADO $>2.0 . \mathrm{CO} ; 2$.

$\longrightarrow,-$, and G. K. Walker, 2005: Global changes of the water cycle intensity. J. Climate, 18, 1591-1608, https://doi.org/ 10.1175/JCLI3357.1.

Bracegirdle, T. J., and S. L. Gray, 2008: An objective climatology of the dynamical forcing of polar lows in the Nordic seas. Int. J. Climatol., 28, 1903-1919, https://doi.org/10.1002/joc.1686.

Browning, K. A., 1990: Organization of clouds and precipitation in extratropical cyclones. Extratropical Cyclones: The Erik Palmen Memorial Volume, C. W. Newton and E. O. Holopainen, Eds., Amer. Meteor. Soc., 129-153.

Brümmer, B., 1996: Boundary-layer modification in wintertime cold-air outbreaks from the Arctic sea ice. Bound.-Layer Meteor., 80, 109-125, https://doi.org/10.1007/BF00119014.

_ 1997: Boundary layer mass, water, and heat budgets in wintertime cold-air outbreaks from the Arctic sea ice. Mon. Wea. Rev., 125, 1824-1837, https://doi.org/10.1175/1520-0493(1997) $125<1824$ :BLMWAH $>2.0$.CO;2.

- 1999: Roll and cell convection in wintertime Arctic cold-air outbreaks. J. Atmos. Sci., 56, 2613-2636, https://doi.org/ 10.1175/1520-0469(1999)056<2613:RACCIW >2.0.CO;2.

_ _ G. Müller, and D. Schröder, 2005: In situ observations in cyclones over Fram Strait. Meteor. Z., 14, 721-734, https:// doi.org/10.1127/0941-2948/2005/0082. 
Bryan, G. H., J. C. Wyngaard, and J. M. Fritsch, 2003: Resolution requirements for the simulation of deep moist convection. Mon. Wea. Rev., 131, 2394-2416, https://doi.org/10.1175/15200493(2003)131<2394:RRFTSO > 2.0.CO;2.

Businger, S., and R. J. Reed, 1989: Cyclogenesis in cold air masses. Wea. Forecasting, 4, 133-156, https://doi.org/10.1175/1520 0434(1989)004<0133:CICAM>2.0.CO;2.

Chechin, D. G., C. Lüpkes, I. A. Repina, and V. M. Gryanik, 2013: Idealized dry quasi 2-D mesoscale simulations of cold-air outbreaks over the marginal sea ice zone with fine and coarse resolution. J. Geophys. Res. Atmos., 118, 8787-8813, https://doi.org/ 10.1002/jgrd.50679.

Cook, P. A., and I. A. Renfrew, 2015: Aircraft-based observations of air-sea turbulent fluxes around the British Isles. Quart. J. Roy. Meteor. Soc., 141, 139-152, https://doi.org/10.1002/ qj. 2345.

Dacre, H. F., and S. L. Gray, 2009: The spatial distribution and evolution characteristics of North Atlantic cyclones. Mon Wea. Rev., 137, 99-115, https://doi.org/10.1175/2008MWR2491.1.

Dee, D., and Coauthors, 2011: The ERA-Interim reanalysis: Configuration and performance of the data assimilation system. Quart. J. Roy. Meteor. Soc., 137, 553-597, https://doi.org/ 10.1002/qj.828.

Doms, G., and Coauthors, 2011: A description of the nonhydrostatic regional COSMO model. Part II: Physical parameterization. Tech. Rep. LM_F90 4.20, Deutscher Wetterdienst, Offenbach, Germany, 154 pp., http://www.cosmo-model.org/content/model/ documentation/core/cosmoPhysParamtr.pdf.

Fairall, C. W., E. F. Bradley, D. P. Rogers, J. B. Edson, and G. S. Young, 1996: Bulk parameterization of air-sea fluxes for tropical ocean-global atmosphere coupled-ocean atmosphere response experiment. J. Geophys. Res., 101, 3747-3764, https:// doi.org/10.1029/95JC03205.

$\longrightarrow,-$, J. E. Hare, A. A. Grachev, and J. B. Edson, 2003: Bulk parameterization of air-sea fluxes: Updates and verification for the COARE algorithm. J. Climate, 16, 571-591, https://doi.org/ 10.1175/1520-0442(2003)016<0571:BPOASF $>2.0 . \mathrm{CO} ; 2$.

Field, P. R., and Coauthors, 2017: Exploring the convective grey zone with regional simulations of a cold air outbreak. Quart. J. Roy. Meteor. Soc., 143, 2537-2555, https://doi.org/10.1002/ qj.3105.

Fletcher, J., S. Mason, and C. Jakob, 2016: The climatology, meteorology, and boundary layer structure of marine cold air outbreaks in both hemispheres. J. Climate, 29, 1999-2014, https://doi.org/10.1175/JCLI-D-15-0268.1.

Grossman, R. L., and A. K. Betts, 1990: Air-sea interaction during an extreme cold air outbreak from the eastern coast of the United States. Mon. Wea. Rev., 118, 324-342, https://doi.org/ 10.1175/1520-0493(1990)118<0324:AIDAEC >2.0.CO;2.

Gryschka, M., J. Fricke, and S. Raasch, 2014: On the impact of forced roll convection on vertical turbulent transport in cold air outbreaks. J. Geophys. Res. Atmos., 119, 12 513-12 532, https://doi.org/10.1002/2014JD022160.

Harden, B. E., I. A. Renfrew, and G. N. Petersen, 2015: Meteorological buoy observations from the central Iceland Sea. J. Geophys. Res. Atmos., 120, 3199-3208, https://doi.org/10.1002/ 2014JD022584.

Hartmann, J., C. Kottmeier, and S. Raasch, 1997: Roll vortices and boundary-layer development during a cold air outbreak. Bound.-Layer Meteor., 84, 45-65, https://doi.org/10.1023/ A:1000392931768.

Hoskins, B. J., M. E. McIntyre, and A. W. Robertson, 1985: On the use and significance of isentropic potential vorticity maps.
Quart. J. Roy. Meteor. Soc., 111, 877-946, https://doi.org/ 10.1002/qj.49711147002.

Iwasaki, T., T. Shoji, Y. Kanno, M. Sawada, M. Ujiie, and K. Takaya, 2014: Isentropic analysis of polar cold airmass streams in the Northern Hemispheric winter. J. Atmos. Sci., 71, 2230-2243, https://doi.org/10.1175/JAS-D-13-058.1.

Jahnke-Bornemann, A., and B. Brümmer, 2008: The Iceland-Lofotes pressure difference: Different states of the North Atlantic lowpressure zone. Tellus, 61A, 466-475, https://doi.org/10.1111/ j.1600-0870.2009.00401.x.

Joussaume, S., R. Sadourny, and J. Jouzel, 1984: A general circulation model of water isotope cycles in the atmosphere. $\mathrm{Na}$ ture, 311, 24-29, https://doi.org/10.1038/311024a0.

Kew, S. F., M. Sprenger, and H. C. Davies, 2010: Potential vorticity anomalies of the lowermost stratosphere: A 10-yr winter climatology. Mon. Wea. Rev., 138, 1234-1249, https://doi.org/ 10.1175/2009MWR3193.1.

Kolstad, E. W., 2011: A global climatology of favourable conditions for polar lows. Quart. J. Roy. Meteor. Soc., 137, 1749-1761, https://doi.org/10.1002/qj.888.

2017: Higher ocean wind speeds during marine cold air outbreaks. Quart. J. Roy. Meteor. Soc., 143, 2084-2092, https:// doi.org/10.1002/qj.3068.

— T. J. Bracegirdle, and I. A. Seierstad, 2009: Marine cold-air outbreaks in the North Atlantic: Temporal distribution and associations with large-scale atmospheric circulation. Climate Dyn., 33, 187-197, https://doi.org/10.1007/s00382-008-0431-5.

Koster, R., J. Jouzel, R. Souzzo, G. Russell, W. Broecker, D. Rind, and P. Eagleson, 1986: Global sources of local precipitation as determined by the NASA/GISS GCM. Geophys. Res. Lett., 13, 121-124, https://doi.org/10.1029/GL013i002p00121.

Kristovich, D. A. R., and Coauthors, 2000: The Lake-Induced Convection Experiment and the Snowband Dynamics Project. Bull. Amer. Meteor. Soc., 81, 519-542, https://doi.org/10.1175/ 1520-0477(2000)081<0519:TLCEAT>2.3.CO;2.

Läderach, A., and H. Sodemann, 2016: A revised picture of the atmospheric moisture residence time. Geophys. Res. Lett., $\mathbf{4 3 ,}$ 924-933, https://doi.org/10.1002/2015GL067449.

Louis, J., 1979: A parametric model of vertical eddy fluxes in the atmosphere. Bound.-Layer Meteor., 17, 187-202, https:// doi.org/10.1007/BF00117978.

Lüpkes, C., and K. H. Schlünzen, 1996: Modelling the Arctic convective boundary-layer with different turbulence parameterizations. Bound.-Layer Meteor., 79, 107-130, https:// doi.org/10.1007/BF00120077.

Madonna, E., H. Wernli, H. Joos, and O. Martius, 2014: Warm conveyor belts in the ERA-Interim dataset (1979-2010). Part I: Climatology and potential vorticity evolution. J. Climate, 27, 3-26, https://doi.org/10.1175/JCLI-D-12-00720.1.

Marshall, J., and F. Schott, 1999: Open-ocean convection: Observations, theory, and models. Rev. Geophys., 37, 1-64, https:// doi.org/10.1029/98RG02739.

Numaguti, A., 1999: Origin and recycling processes of precipitating water over the Eurasian continent: Experiments using an atmospheric general circulation model. J. Geophys. Res., 104, 1957-1972, https://doi.org/10.1029/1998JD200026.

Pagowski, M., and G. W. K. Moore, 2001: A numerical study of an extreme cold-air outbreak over the Labrador Sea: Sea ice, air-sea interaction, and development of polar lows. Mon. Wea. Rev., 129, 47-72, https://doi.org/10.1175/1520-0493(2001) 129<0047:ANSOAE > 2.0.CO;2.

Papritz, L., and S. Pfahl, 2016: Importance of latent heating in mesocyclones for the decay of cold air outbreaks: A numerical 
process study from the Pacific sector of the Southern Ocean. Mon. Wea. Rev., 144, 315-336, https://doi.org/10.1175/MWRD-15-0268.1.

- and T. Spengler, 2017: A Lagrangian climatology of wintertime cold air outbreaks in the Irminger and Nordic seas and their role in shaping air-sea heat fluxes. J. Climate, 30, 2717 2737, https://doi.org/10.1175/JCLI-D-16-0605.1.

_- and C. Grams, 2018: Linking low-frequency large-scale circulation patterns to cold air outbreak formation in the northeastern North Atlantic. Geophys. Res. Lett., 45, 2542-2553, https://doi.org/10.1002/2017GL076921.

— , S. Pfahl, H. Sodemann, and H. Wernli, 2015: A climatology of cold air outbreaks and their impact on air-sea heat fluxes in the high-latitude South Pacific. J. Climate, 28, 342-364, https:// doi.org/10.1175/JCLI-D-14-00482.1.

Pfahl, S., and H. Wernli, 2012: Quantifying the relevance of cyclones for precipitation extremes. J. Climate, 25, 6770-6780, https://doi.org/10.1175/JCLI-D-11-00705.1.

— global precipitation? Climate Past, 10, 771-781, https://doi.org/ 10.5194/cp-10-771-2014.

-, H. Wernli, and K. Yoshimura, 2012: The isotopic composition of precipitation from a winter storm-A case study with the limited-area model COSMO ISO. Atmos. Chem. Phys., 12, 1629-1648, https://doi.org/10.5194/acp-12-1629-2012.

— E. Madonna, M. Boettcher, H. Joos, and H. Wernli, 2014: Warm conveyor belts in the ERA-Interim dataset (1979-2010). Part II: Moisture origin and relevance for precipitation. J. Climate, 27, 27-40, https://doi.org/10.1175/JCLI-D-1300223.1.

Rasmussen, E., and J. Turner, 2003: Polar Lows: Mesoscale Weather Systems in the Polar Regions. Cambridge University Press, 612 pp.

Renfrew, I. A., and G. W. K. Moore, 1999: An extreme cold-air outbreak over the Labrador Sea: Roll vortices and air-sea interaction. Mon. Wea. Rev., 127, 2379-2394, https://doi.org/ 10.1175/1520-0493(1999)127<2379:AECAOO>2.0.CO;2.

Schröder, D., G. Heinemann, and S. Willmes, 2011: The impact of a thermodynamic sea-ice module in the COSMO numerical weather prediction model on simulations for the Laptev Sea, Siberian Arctic. Polar Res., 30, 6334, https://doi.org/10.3402/ polar.v30i0.6334.

Segtnan, O. H., T. Furevik, and A. D. Jenkins, 2011: Heat and freshwater budgets of the Nordic seas computed from atmospheric reanalysis and ocean observations. J. Geophys. Res., 116, C11003, https://doi.org/10.1029/2011JC006939.

Shapiro, M. A., L. S. Fedor, and T. Hampel, 1987: Research aircraft measurements of a polar low over the Norwegian Sea. Tellus, 39A, 272-306, https://doi.org/10.1111/j.1600-0870.1987.tb00309.x.

Škerlak, B., M. Sprenger, S. Pfahl, E. Tyrlis, and H. Wernli, 2015: Tropopause folds in ERA-Interim: Global climatology and relation to extreme weather events. J. Geophys. Res. Atmos., 120, 4860-4877, https://doi.org/10.1002/2014JD022787.

Skyllingstad, E. D., and J. B. Edson, 2009: Large-eddy simulation of moist convection during a cold air outbreak over the Gulf Stream. J. Atmos. Sci., 66, 1274-1293, https://doi.org/10.1175/ 2008JAS2755.1.

Sodemann, H., and A. Stohl, 2013: Moisture origin and meridional transport in atmospheric rivers, and their association with multiple cyclones. Mon. Wea. Rev., 141, 2850-2868, https:// doi.org/10.1175/MWR-D-12-00256.1.
- H. Wernli, and C. Schwierz, 2009: Sources of water vapour contributing to the Elbe flood in August 2002-A tagging study in a mesoscale model. Quart. J. Roy. Meteor. Soc., 135, 205-223, https://doi.org/10.1002/qj.374.

Spensberger, C., and M. Sprenger, 2018: Beyond cold and warm: An objective classification for maritime midlatitude fronts. Quart. J. Roy. Meteor. Soc., 144, 261-277, https://doi.org/10.1002/qj.3199.

Steen-Larsen, H. C., and Coauthors, 2015: Moisture sources and synoptic to seasonal variability of North Atlantic water vapor isotopic composition. J. Geophys. Res. Atmos., 120, 57575774, https://doi.org/10.1002/2015JD023234.

Steppeler, J., G. Doms, U. Schättler, H. W. Bitzer, A. Gassmann, U. Damrath, and G. Gregoric, 2003: Meso-gamma scale forecasts using the nonhydrostatic model LM. Meteor. Atmos. Phys., 82, 75-96, https://doi.org/10.1007/s00703-001-0592-9.

Stohl, A., C. Forster, and H. Sodemann, 2008: Remote sources of water vapor forming precipitation on the Norwegian west coast at $60^{\circ} \mathrm{N}-\mathrm{A}$ tale of hurricanes and an atmospheric river. J. Geophys. Res., 113, D05102, https://doi.org/10.1029/2007JD009006.

Terpstra, A., T. Spengler, and R. W. Moore, 2015: Idealised simulations of polar low development in an Arctic moist-baroclinic environment. Quart. J. Roy. Meteor. Soc., 141, 1987-1996, https:// doi.org/10.1002/qj.2507.

Tiedtke, M., 1989: A comprehensive mass flux scheme for cumulus parameterization in large-scale models. Mon. Wea. Rev., 117, 1779-1800, https://doi.org/10.1175/1520-0493(1989)117<1779: ACMFSF $>2.0 . \mathrm{CO} ; 2$.

Tomassini, L., P. R. Field, R. Honnert, S. Malardel, R. McTaggartCowan, K. Saitou, A. T. Noda, and A. Seifert, 2017: The "grey zone" cold air outbreak global model intercomparison: A cross evaluation using large-eddy simulations. J. Adv. Model. Earth Syst., 9, 39-64, https://doi.org/10.1002/2016MS000822.

Vannière, B., A. Czaja, H. Dacre, T. Woollings, and R. Parfitt, 2016: A potential vorticity signature for the cold sector of winter extratropical cyclones. Quart. J. Roy. Meteor. Soc., 142, 432-442, https://doi.org/10.1002/qj.2662.

Vihma, T., and B. Brümmer, 2002: Observations and modelling of the on-ice and off-ice air flow over the Northern Baltic Sea. Bound.-Layer Meteor., 103, 1-27, https://doi.org/10.1023/ A:1014566530774.

Wacker, U., K. V. Jayaraman Potty, C. Lüpkes, J. Hartmann, and M. Raschendorfer, 2005: A case study on a polar cold air outbreak over Fram Strait using a mesoscale weather prediction model. Bound.-Layer Meteor., 117, 301-336, https:// doi.org/10.1007/s10546-005-2189-1.

Wang, Y., B. Geerts, and Y. Chen, 2016: Vertical structure of boundary layer convection during cold-air outbreaks at Barrow, Alaska. J. Geophys. Res. Atmos., 121, 399-412, https:// doi.org/10.1002/2015JD023506.

Wernli, H., and C. Schwierz, 2006: Surface cyclones in the ERA-40 dataset (1958-2001). Part I: Novel identification method and global climatology. J. Atmos. Sci., 63, 2486-2507, https:// doi.org/10.1175/JAS3766.1.

Winschall, A., S. Pfahl, H. Sodemann, and H. Wernli, 2012: Impact of North Atlantic evaporation hot spots on southern Alpine heavy precipitation events. Quart. J. Roy. Meteor. Soc., 138 , 1245-1258, https://doi.org/10.1002/qj.987.

$-, \ldots, \ldots$, and 2014: Comparison of Eulerian and Lagrangian moisture source diagnostics-The flood event in eastern Europe in May 2010. Atmos. Chem. Phys., 14, 66056619, https://doi.org/10.5194/acp-14-6605-2014. 